\title{
Development of Epoxy Based Surface Tolerant Coating Improvised with Zn Dust and MIO on Steel Surfaces
}

\author{
Rachna Jain, ${ }^{1}$ Manish Wasnik, ${ }^{2}$ Amit Sharma, ${ }^{3}$ Manish Kr Bhadu, \\ T. K. Rout, ${ }^{1}$ and A. S. Khanna ${ }^{2}$ \\ ${ }^{1}$ TATA Steel Ltd., Jamshedpur, India \\ ${ }^{2}$ IIT Bombay, India \\ ${ }^{3}$ Stanvac-Superon Group, Gurgaon, India
}

Correspondence should be addressed to Rachna Jain; rchn.jain@gmail.com

Received 16 November 2013; Revised 28 January 2014; Accepted 18 February 2014; Published 3 April 2014

Academic Editor: Fahmina Zafar

Copyright (C) 2014 Rachna Jain et al. This is an open access article distributed under the Creative Commons Attribution License, which permits unrestricted use, distribution, and reproduction in any medium, provided the original work is properly cited.

\begin{abstract}
Couple of high strength and flexible surface tolerant coatings were designed for oil contaminated, rusty, and minimally prepared steel surfaces. These coatings are to have strong interfacial adhesion due to low surface tension and sustain more than $5 \mathrm{MPa}$ pull out force consistently. The effect of optimized concentration of zinc dust and micaceous iron oxide (MIO) as pigments is evaluated for these surface tolerant coating systems. It has been noticed that the presence of these two ingredients has enhanced corrosion resistance more than several times as compared to commercially available coating systems. The corrosion simulation test in $3.5 \mathrm{wt} . \%$ $\mathrm{NaCl}$ has evident for significant improvement in terms of delaying blistering and delamination. The high pore resistance $\left(R_{p}\right)$ indicates the slow migration of ions and water into the substrate and coating interface, which could be the reason of the improvement in corrosion process.
\end{abstract}

\section{Introduction}

Surface tolerant coatings are the coatings which can be applied over moist, chemically contaminated or rusty steel, old painted surface, and other minimally prepared surfaces. Most commonly used are red lead alkyd, epoxy mastic, aluminum epoxy mastic, moisture-cured urethane, coal tar mastic, modified wax, and grease based materials. The addition of zinc and micaceous iron oxide (MIO) in the binder provide the cathodic and barrier protection with an excellent surface tolerant tendency. The coating properties of a "fair" surface tolerant coating are excellent penetration, wettability, adherence ability under dry and wet conditions, high electrical resistance to provide a barrier between anodic and cathodic sites of corrosion cells, excellent barrier properties such as impermeability to water, oxygen, and ions, neutralization of chloride, bromide and sulfate salts, and ability to suppress internal stress. Surface tolerant coatings do not require high profile surface preparation so no generation of fine dust, abrasive particulates but abrasive blast cleaning, produces toxic debris and its disposal may be harmful. Surface tolerant coatings can be a replacement of high performance marine coatings systems (required a high degree of surface cleanliness). No cleanliness of high performance marine coating systems may cause the potential degradation of performance and reduction in durability of high performance corrosion control coating systems [1-3].

The surface tolerant coatings are mainly used as maintenance and anticorrosive property in marine and industrial environments. The challenge of reducing the level of surface preparation without degrading performance also exists in other areas of industrial coatings such as chemical plants. To overcome this apparent disparity between levels of cleanliness and coating performance, many new coating products are being formulated to accommodate reduced cleaning levels [4].

Epoxy resin is known for its high range of attainable properties and versatility with excellent surface tolerance tendency due to its chemical structure in curing conditions. High crosslinking tendency during curing makes the coating 


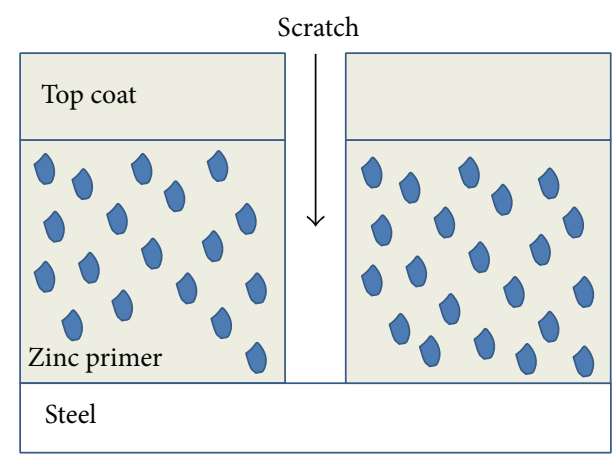

(a)

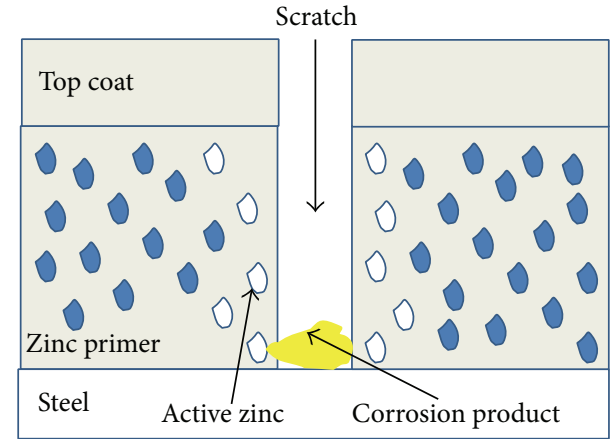

(b)

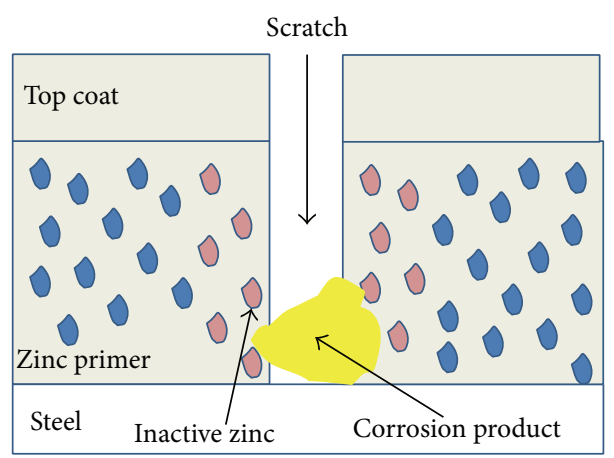

(c)

FIGURE 1: Mechanisms of a zinc coating system: (a) scribe or scratch is introduced down to the steel surface; (b) near scratch, zinc becomes active, while zinc-iron corrosion products are being built up; (c) zinc becomes inactive, but the coating provides only barrier and inhibitive protection.

tough with excellent surface protection, chemical resistant, flexible with high strength, hard, and good heat and electrical resistant $[5,6]$. Other important applications include repair of cracks and fissures in structural concrete above or underwater and as adhesives for ceramics. Apart from its excellent adhesion, the surface tolerant properties also depend on the pigments, additives in the epoxy coating, which is also responsible for cathodic as well as barrier protection $[7,8]$.

The viscosity, adhesion, flexibility, impact resistance, and substrate wetting directly depend on molecular weight of unreacted epoxy resin, while cross-linking density, solvent resistance, and hardness decrease as molecular weight of unreacted epoxy resin decreases [9]. Formation of epoxy resin is the combination of bisphenol A (used for high temperature and chemical resistance) and epichlorohydrin in presence of alkaline and the resultant is diglycidyl ether of bisphenol A (DGEBA) which is formed after extracting unreacted phenol and acetone [10].

Epoxy resins have the ability to transform readily from the liquid state to tough and hard solids. This hardening is accomplished by addition of chemically active reagent known as curing agent (hardener). Dry time, penetration, and wettability depend upon hardener which cross-linked with resin and provide high chemical resistant with good flexibility. In this paper, cycloaliphatic amines are used as a hardener (room temperature curing and convenient handling) because these amines provide good adhesion as their compatibility with epoxy and easy availability of lone pairs on nitrogen atom (because of noninvolvement in aromaticity) to zinc and iron surfaces (chemiadsorption) as compared to aromatic amines. There is a crosslinking structure formed after curing which is in between cycloaliphatic amine and epoxy resin due to the polar bonds interaction of epoxy resin with available lone pairs of nitrogen atom of cycloaliphatic amine [9-11].

Many pigments can be used with epoxy resin, but we have chosen zinc pigment because of its lower potential. The performance of zinc depends on ratio of pigment volume concentration (PVC) to critical pigment volume concentration (CPVC). If the ratio is $<1$, then it will provide the barrier protection. If the ratio is $>1$, then it will provide the cathodic protection but influences its permeability and mechanical properties. But the sacrificial action of zinc starts up only when there is uninterrupted contact between metal particles, that is, infiltration path [12]. So, zinc primers are widely used in various aggressive atmospheres such as offshore, industrial, and so forth, because of its distinctive property of metal protection even after the scribe or any mechanical damage to the coating which provides good sacrificial protection at the early stage and the alkaline nature and low solubility of corrosion products of zinc provides additional barrier protection at the later stage as shown in Figure 1 [13].

Type of pigment or filler used in organic coating acts as barrier and is of crucial importance to the pigment-polymer matrix interaction because undercoat layer increases the free 


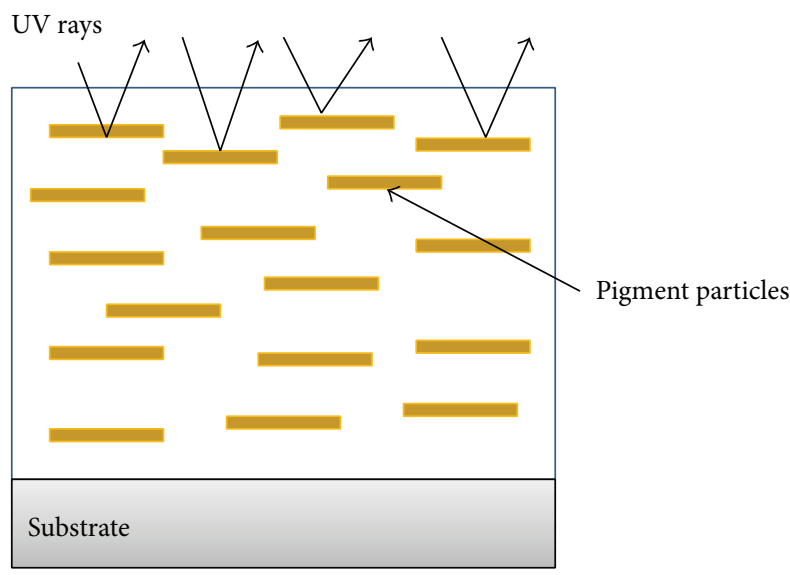

FIGURE 2: The flip-flop effect showing protection against ultraviolet (UV).

mean path for the diffusion of water, oxygen, and ions. The most common lamellar pigments are MIO, flakes of glass, metallic $\mathrm{Al}$ particles, $\mathrm{Zn}$ dust, and so forth [14]. Zinc with epoxies provides films with moderate porosity. Specially formulated intermediate and/or topcoats are required to overcome blistering over such zinc-based primers (zinc primer is the zinc dust spherical, lamellar, or combination of both that is dispersed in organic epoxies resin). By lowering the zinc pigment content in the formulation, application blistering problem can be solved by scarifying the primer's galvanic properties. Performance of zinc primers also depends on the morphology of the $\mathrm{Zn}$ particle; smaller and lamellar particles give better results than larger and spherical particles. [15].

Figure 3 shows the lamellar MIO creating tortuous path for water and micaceous iron oxide (MIO) is iron oxide in a form that resembles mica, a highly structured, layered mineral. The lamellar shape of this micaceous form of iron oxide (high volumetric pigment concentration) offers greatly enhanced barrier protection due to its tendency to orient parallel to the substrate thereby increase the mean free path for the diffusion of the aggressive species. The lamellar nature and shiny surface appearance of MIO pigments offer ultraviolet protection (reflecting barrier to the light) and protect against blistering and delamination to the underlying epoxy system. This mechanism of protection is known as flip-flop effect as shown in Figure 2. Epoxy and enamel based coatings normally chalk on exposure to ultraviolet rays; however, in coatings pigmented with MIO, only the resin on the surface of the uppermost MIO particles is exposed to ultraviolet rays and will chalk [14].

In this paper, solvent borne epoxy mastic as a primer was synthesized by using bisphenol A based epoxy resin modifying with zinc dust and MIO. It was observed that MIO and Zinc dust are used in coatings as a barrier and cathodic protection, respectively, and it improves mechanical and corrosion properties of coatings. The emphasis was given to the development of MIO and Zinc dust incorporated into epoxy based coating. So in order to achieve the objective, two types of systems (two types of surface tolerant coating systems STC1 and STC2 were developed: (1) STC1 comprises two coat of epoxy mastic primer with zinc dust, and (2) STC2
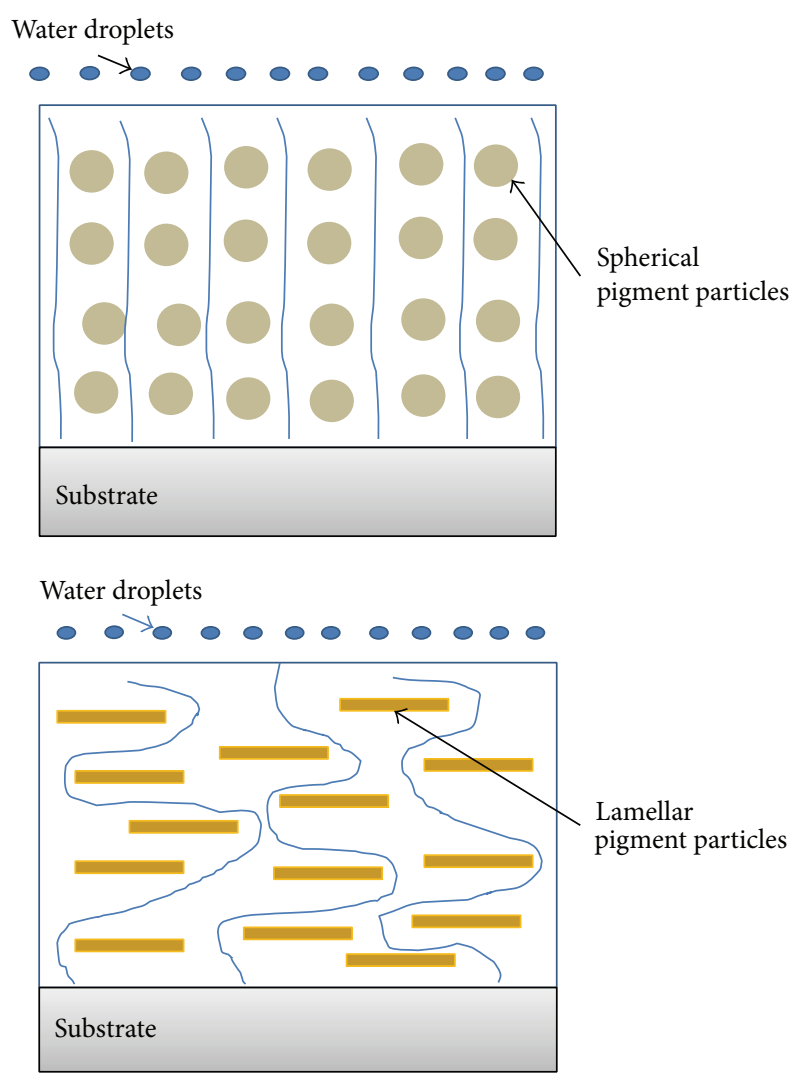

FIGURE 3: Lamellar MIO creating tortuous path for water when the water permeates.

comprises two coat of epoxy mastic with MIO) were prepared and characterized with optimized concentration of MIO and zinc dust with commercially available coating systems which are not suitable for application on partially cleaned surface, prepared according to St $2 / \mathrm{St} 3$ standards. The coating was evaluated for mechanical and corrosion resistance properties for steel as a primer coating.

\section{Experimental Procedure}

\subsection{Materials and Reagents}

(1) Epoxy resins: unmodified epoxy resin derived from bisphenol A-epoxy equivalent weight (EEW): 185190. Source: Aditya birla chemicals (Thailand) Ltd., Thailand.

(2) Amine hardener or curing agent (source: Huntsman advance materials): formulated polyamidoamine adduct with catalyst.

(3) Pigments and fillers:

micaceous iron oxide $(45-50 \mu)-11 \%$, calcite (300 mesh), talc (300 mesh), silica powder (300 mesh), and mica (300 mesh) (source: D.K. Corporation (DKC), Indore);

superfine zinc dust $(5 \mu)-11 \%$ (source: Bansal trading company);

titanium dioxide (source: DuPont). 
TABLE 1: STC primer base formulations (mixing ratio ( $5: 1$ by volume)).

\begin{tabular}{|c|c|c|c|c|c|c|}
\hline \multirow{2}{*}{ S.N. } & \multicolumn{2}{|c|}{ STC1: primer base } & \multicolumn{2}{|c|}{ STC2: primer base } & \multicolumn{2}{|l|}{ Primer's hardener } \\
\hline & Ingredients & Wt.\% & Ingredients & Wt.\% & Ingredients & Wt.\% \\
\hline 1 & Epoxy resin & $20 \%$ & Epoxy resin & $20 \%$ & Modified polyamidoamine adduct & $94.5 \%$ \\
\hline \multirow{3}{*}{2} & Pigments & & Pigments & & \multirow{3}{*}{ Catalyst: 2,4,6-Tris (dimethyl amino methyl) phenol } & \multirow{3}{*}{$5 \%$} \\
\hline & $\mathrm{TiO}_{2}$ & $5 \%$ & $\mathrm{TiO}_{2}$ & $5 \%$ & & \\
\hline & Zinc dust & $25 \%$ & $\mathrm{MIO}$ & $30 \%$ & & \\
\hline \multirow{3}{*}{3} & Thixotropic agent & $0.5 \%$ & Thixotropic agent & $0.5 \%$ & \multirow{8}{*}{ Thixatrol ST antisettling agent } & \multirow{8}{*}{$0.5 \%$} \\
\hline & Leveling agent & $0.5 \%$ & Leveling agent & $0.5 \%$ & & \\
\hline & Dispersing agent & $1 \%$ & Dispersing agent & $1 \%$ & & \\
\hline \multirow{5}{*}{4} & Fillers & & Fillers & & & \\
\hline & Talc & $5 \%$ & Talc & $5 \%$ & & \\
\hline & Calcite & $10 \%$ & Calcite & $10 \%$ & & \\
\hline & Silica powder & $10 \%$ & Silica powder & $10 \%$ & & \\
\hline & Mica & $10 \%$ & & & & \\
\hline \multirow{3}{*}{5} & Polar solvent & $3 \%$ & Polar solvent & $3 \%$ & & \\
\hline & Xylene & $7 \%$ & Xylene & $10 \%$ & & \\
\hline & Methyl isobutyl ketone & $3 \%$ & Methyl isobutyl ketone & $5 \%$ & & \\
\hline
\end{tabular}

(4) Thinner: polar solvents (source: Monument chemicals).

(5) Additives: silicone based thixotropic agent (source: Elementis specialties), leveling and surface tension reducing agent, and defoamer and adhesion promotor (source: BYK additives and instruments).

(6) Substrates used (source: Tata Steel, Jamshedpur): hot rolled coil sheet grinded as per Swedish standard st2 and st3.

\subsection{Coating Formulations. See Table 1.}

2.3. Processing for Formation, Surface Preparation, and then Application. STC1 and STC2 primer base synthesis as per Table 1.

(a) Premixing stage: the calculated amount of epoxy resin stirred with $3 \%$ of polar solvent at high-speed mixer for 10 minutes. When temperature reaches up to $40^{\circ} \mathrm{C}$ of resin, pour fixed amount of thixotropic agent and mix for 20 minutes. It becomes like slurry.

(b) Grinding stage:

(i) the uniform dispersion of pigments was carried out with slurry and dispersing agent in single disc bead mill, using $1 \mathrm{~mm}$ sized glass beads as grinding media filled up to disc level. The process was continued until 30 minutes;

(ii) the uniform dispersion of extenders/fillers was carried out and continued until fineness of dispersion. The estimated time for grinding was 22.5 hours until hegmann gauge 5 was achieved.

(c) Thinning stage: here, the uniformly distributed pigment slurry was added with left over resin solution, solvents, and leveling additive to adjust the viscosity and flow property as required. The thinning was done in high-speed disk disperser for approximately 30 minutes.

2.4. Coating Characterization. Table 2 summarizes the properties of different types of liquid polymer base and hardeners with their significant FT-IR peaks and surface tension. STC1 and STC2 both have lower surface tension which proves their more surface tolerant tendency as compared to others.

2.5. Surface Preparation and Film Deposition of Substrate. The surface preparation was carried out by manual method as per Swedish standard st 2 and st 3 . The substrate was subjected to cleaning by means of emery paper of $60 \mu \mathrm{m}$ grit size then cleaned with acetone to remove oil, grease, and nonadherent dirt particles. The prepared substrates were applied with various primer and top coat systems. Here, the application was carried out by means of brush application method. Applied coating thickness of primer after drying in one coat was maintained up to $100 \mu \mathrm{m}$, and then second coat was applied after nail hardness of the coating. The total thickness of dried coating was obtained up to $200 \mu \mathrm{m}$. The hard dry curing time was approximately $8-10$ hours.

2.6. Parameters of Applicability of Coating Systems. Table 3 summarizes the applicability of different types of coatings in different surface conditions which is the minimum passing criteria to be any surface tolerant coating. This criterion can be justified by their value of pull off adhesion and making the film uniform. From this table, it is observed that all benchmark products are not capable to make a uniform film over moist, wet, and oil contaminated surfaces (no pull off adhesion possible), but STC1 and STC2 are both capable of making the uniform film over moist, wet, and 
TABLE 2: In can properties of the various coatings.

\begin{tabular}{|c|c|c|c|c|c|c|}
\hline Systems & $\begin{array}{l}\text { High constitute of } \\
\text { ingredients }\end{array}$ & Polymer base & Cross-linker & Hard dry & Main FT-IR peaks & $\begin{array}{l}\text { Surface tension } \\
\text { (newton/meter) }\end{array}$ \\
\hline Benchmark 1 & $\mathrm{Ti}, \mathrm{Mg}, \mathrm{Si}$, and $\mathrm{Al}$ & Epoxy resin & $\begin{array}{l}\text { Triethylenetetramine } \\
\text { with catalyst }\end{array}$ & 14-16 hours & Strong band & 30.42 \\
\hline Benchmark 2 & $\begin{array}{l}\text { Si and little amount } \\
\text { of } \mathrm{Ti} \text { and } \mathrm{Mg}\end{array}$ & Epoxy resin & $\begin{array}{c}\text { Triethylenetetramine } \\
\text { with catalyst }\end{array}$ & 14-16 hours & $\begin{array}{l}\mathrm{Si}-\mathrm{O}_{\text {(asymm. stret) }} \\
\text { included }\end{array}$ & 31.75 \\
\hline Benchmark 3 & $\begin{array}{l}\text { Si and little } \\
\text { amount of } \mathrm{Ti}\end{array}$ & Epoxy resin & $\begin{array}{c}\text { Triethylenetetramine } \\
\text { with catalyst }\end{array}$ & 12-14 hours & $\begin{array}{l}\mathrm{Ti}-\mathrm{O}_{(\text {Stret }),-} \\
800-1110 \mathrm{~cm}^{-1}\end{array}$ & 33.61 \\
\hline STC1 & $\mathrm{Zn}, \mathrm{Ti}, \mathrm{Si}$ & $\begin{array}{c}\text { Bisphenol A based } \\
\text { epoxy resin with } \\
\text { Zn dust }\end{array}$ & $\begin{array}{c}\text { Fomulated } \\
\text { polyamidoamine } \\
\text { adduct }\end{array}$ & 8-10 hours & $\mathrm{Zn}-\mathrm{O}$ at $454 \mathrm{~cm}^{-1}$ & 29.92 \\
\hline STC2 & $\mathrm{Fe}, \mathrm{Ti}, \mathrm{Si}$ & $\begin{array}{l}\text { Bisphenol A based } \\
\text { epoxy resin with } \\
\text { MIO flakes }\end{array}$ & $\begin{array}{c}\text { Fomulated } \\
\text { polyamidoamine } \\
\text { adduct }\end{array}$ & 8-10 hours & $\mathrm{Fe}-\mathrm{O}$ at $560 \mathrm{~cm}^{-1}$ & 29.20 \\
\hline
\end{tabular}

TABLE 3: Tests for evaluating uniformity and adhesion properties of the films.

\begin{tabular}{|c|c|c|c|c|c|c|}
\hline & \multirow{2}{*}{ Surface conditions } & \multicolumn{5}{|c|}{ Systems } \\
\hline & & Benchmark 1 & Benchmark 2 & Benchmark 3 & STC1 & STC2 \\
\hline \multirow{3}{*}{ Applicability } & Moisture & $\begin{array}{l}\text { No uniform film } \\
\text { formation }\end{array}$ & $\begin{array}{l}\text { No uniform film } \\
\text { formation }\end{array}$ & $\begin{array}{l}\text { No uniform film } \\
\text { formation }\end{array}$ & $\begin{array}{l}\text { Uniform film } \\
\text { formed }\end{array}$ & $\begin{array}{l}\text { Uniform film } \\
\text { formed }\end{array}$ \\
\hline & Oil contaminated & $\begin{array}{l}\text { No uniform film } \\
\text { formation }\end{array}$ & $\begin{array}{l}\text { No uniform film } \\
\text { formation }\end{array}$ & $\begin{array}{l}\text { No uniform film } \\
\text { formation }\end{array}$ & $\begin{array}{l}\text { Uniform film } \\
\text { formed }\end{array}$ & $\begin{array}{l}\text { Uniform film } \\
\text { formed }\end{array}$ \\
\hline & $\begin{array}{l}\text { ST2/ST3 } \\
\text { (properly } \\
\text { prepared) }\end{array}$ & $\begin{array}{l}\text { Uniform film } \\
\text { formed }\end{array}$ & $\begin{array}{l}\text { Uniform film } \\
\text { formed }\end{array}$ & $\begin{array}{l}\text { Uniform film } \\
\text { formed }\end{array}$ & $\begin{array}{l}\text { Uniform film } \\
\text { formed }\end{array}$ & $\begin{array}{l}\text { Uniform film } \\
\text { formed }\end{array}$ \\
\hline \multirow{3}{*}{$\begin{array}{l}\text { Pull off } \\
\text { adhesion } \\
\text { (PSI) }\end{array}$} & Moist & $\begin{array}{l}\text { Not possible as no } \\
\text { adhesion/uniform } \\
\text { film formation } \\
\text { because of high } \\
\text { surface tension }\end{array}$ & $\begin{array}{l}\text { Not possible as no } \\
\text { adhesion/uniform } \\
\text { film formation } \\
\text { because of high } \\
\text { surface tension }\end{array}$ & $\begin{array}{l}\text { Not possible as no } \\
\text { adhesion/uniform } \\
\text { film formation } \\
\text { because of high } \\
\text { surface tension }\end{array}$ & $\begin{array}{l}\text { Tested and found } \\
\text { to be } 4.9 \text { (cohesive } \\
\text { failure }\end{array}$ & $\begin{array}{c}\text { Tested and found } \\
\text { to be } 4.7 \text { (cohesive } \\
\text { failure) }\end{array}$ \\
\hline & Oil contaminated & $\begin{array}{l}\text { Not possible as no } \\
\text { adhesion/uniform } \\
\text { film formation } \\
\text { because of high } \\
\text { surface tension }\end{array}$ & $\begin{array}{l}\text { Not possible as no } \\
\text { adhesion/uniform } \\
\text { film formation } \\
\text { because of high } \\
\text { surface tension }\end{array}$ & $\begin{array}{l}\text { Not possible as no } \\
\text { adhesion/uniform } \\
\text { film formation }\end{array}$ & $\begin{array}{l}\text { Tested and found } \\
\text { to be } \\
\text { 4.8 MPa (cohesive } \\
\text { failure) }\end{array}$ & $\begin{array}{l}\text { Tested and found } \\
\text { to be } 4.6 \text { (cohesive } \\
\text { failure) }\end{array}$ \\
\hline & $\begin{array}{l}\text { ST2 (thoroughly } \\
\text { prepared) }\end{array}$ & $\begin{array}{c}5 \mathrm{MPa} \\
\text { (adhesion failure) }\end{array}$ & $\begin{array}{c}5.4 \mathrm{MPa} \\
\text { (cohesive failure) }\end{array}$ & $\begin{array}{c}4.9 \mathrm{MPa} \\
\text { (adhesion failure) }\end{array}$ & $\begin{array}{c}\text { 5.4 MPa (cohesive } \\
\text { failure) }\end{array}$ & $\begin{array}{c}5.2 \mathrm{MPa} \text { (cohesive } \\
\text { failure) }\end{array}$ \\
\hline
\end{tabular}

oil contaminated surfaces so pull off adhesion test can be done over these surfaces (passing criteria to be a surface tolerant coating). All products form uniform film on properly prepared surfaces.

\section{Results and Discussions}

3.1. Chemical Bonding Analysis by FT-IR Spectroscopy. All spectra were recorded ranging from 3300 to $450 \mathrm{~cm}^{-1}$ wave number by using Magna-IR TM spectrometer 550 (Nicolet) equipped with DTGS detector and averaging of 32 scans. Chemical bonding between the molecules was characterized by FT-IR spectra. FT-IR spectroscopy is a method to detect functional groups by transition in vibrational level of the molecules like aliphatic $\mathrm{CH}_{3}$ stretching falls in $2850-3000 \mathrm{~cm}^{-1}$. Absorption peaks of other functional groups involved in coating systems are shown in Table 4 and Figure 4. The presence of the absorption peaks of $\mathrm{CH}_{3}$ stretching and C-N stretching shows that the basic structure of base polymer matrix of STC2 is not changed after the addition of MIO. While in benchmark products, there are no significant absorption peaks of $\mathrm{Fe}-\mathrm{O}$ and $\mathrm{Zn}-\mathrm{O}$ in spectra as shown in Figure 4 and Table 4 which suggest no metallic oxide present in the benchmark coating systems.

3.2. Surface Morphology by Sem/Edax Analysis. Scanning electron microscopy pictures were taken using Hitachi S$3400 \mathrm{~N}$ microscope (acceleration voltage $15 \mathrm{kV}$ ).

SEM was used to determine the sample surface topography and to get the idea of the distribution of the pigments present in primer STC1 and primer STC2. EDAX analysis was used to evaluate elemental composition of the coatings on the surface region. SEM micrographs of primer STC1 and 
TABLE 4: Chemical bonding analysis by FT-IR spectroscopy.

\begin{tabular}{ll}
\hline Wave number $\left(\mathrm{cm}^{-1}\right)$ & Chemical analysis \\
\hline $3000-2850 \mathrm{~cm}^{-1}$ & Aliphatic $-\mathrm{CH}_{2}$ and $\mathrm{CH}_{3 \text { stretching }}$ \\
$900-1250 \mathrm{~cm}^{-1}$ & $-\mathrm{C}-\mathrm{N}_{\text {stretching }}$ : shows the reaction of epoxy and aliphatic amine \\
$454 \mathrm{~cm}^{-1}$ & $\mathrm{Zn}-\mathrm{O}_{\text {stretching }}$ vibration: Obtained in STC1 only \\
$560 \mathrm{~cm}^{-1}$ & $\mathrm{Fe}-\mathrm{O}_{\text {stretching }}$ Obtained in STC2 only \\
$1000-1260 \mathrm{~cm}^{-1}$ & $-\mathrm{C}-\mathrm{O}$ coupled with C-C $\Longrightarrow \mathrm{C}-\mathrm{C}-\mathrm{O}$ \\
$800-1110 \mathrm{~cm}^{-1}$ & Strong band $\mathrm{Si}-\mathrm{O}_{\text {asymmetric stretching }}$ included Ti- $\mathrm{O}_{\text {Stretching }}$ \\
$600-950 \mathrm{~cm}^{-1}$ & Ti-O $\mathrm{O}_{\text {(stretching) }}$ only, the bands of some widespread pigments overlapped with several other pigments \\
$1600-1650 \mathrm{~cm}^{-1}$ & Quadrant Stretching of phenyl ring which shows the presence of epoxy resin \\
$1490-1540 \mathrm{~cm}^{-1}$ & Aromatic $\sqrt{C-C}_{\mathrm{C}}$ which shows the presence of epoxy resin \\
\hline
\end{tabular}
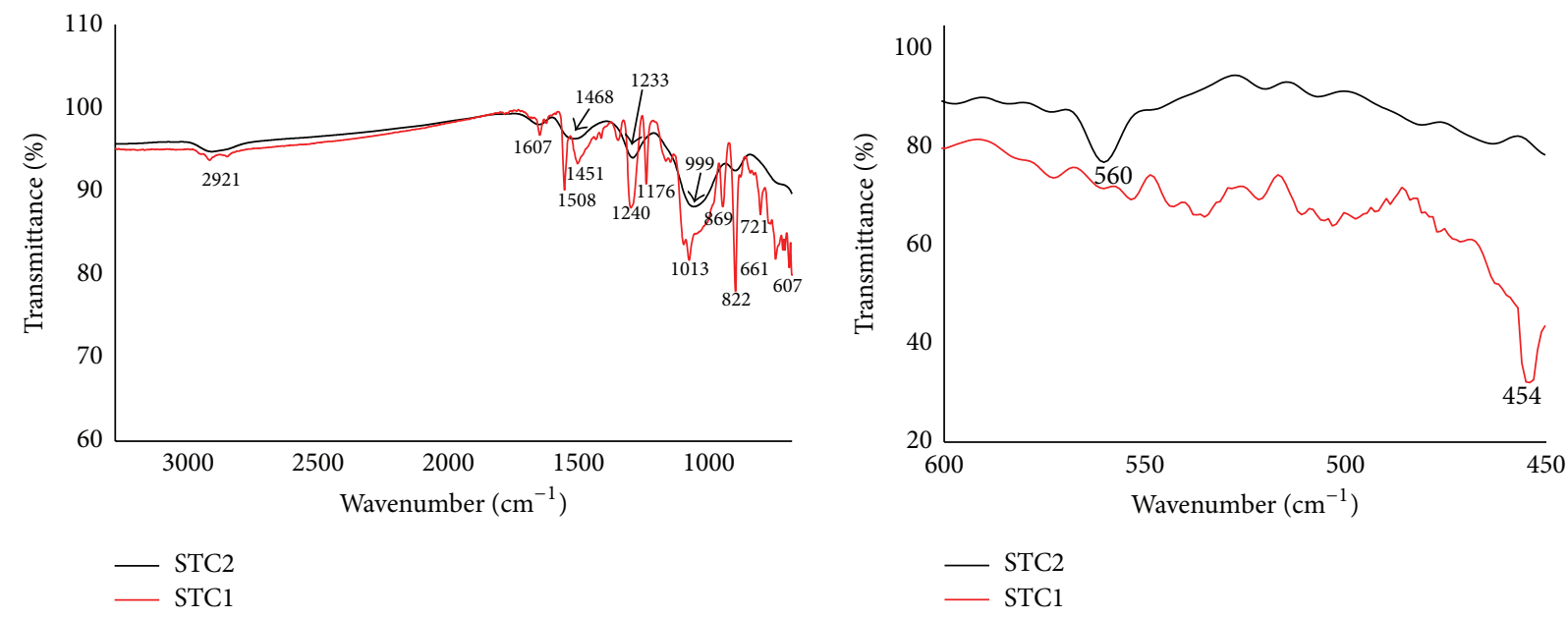

(a)
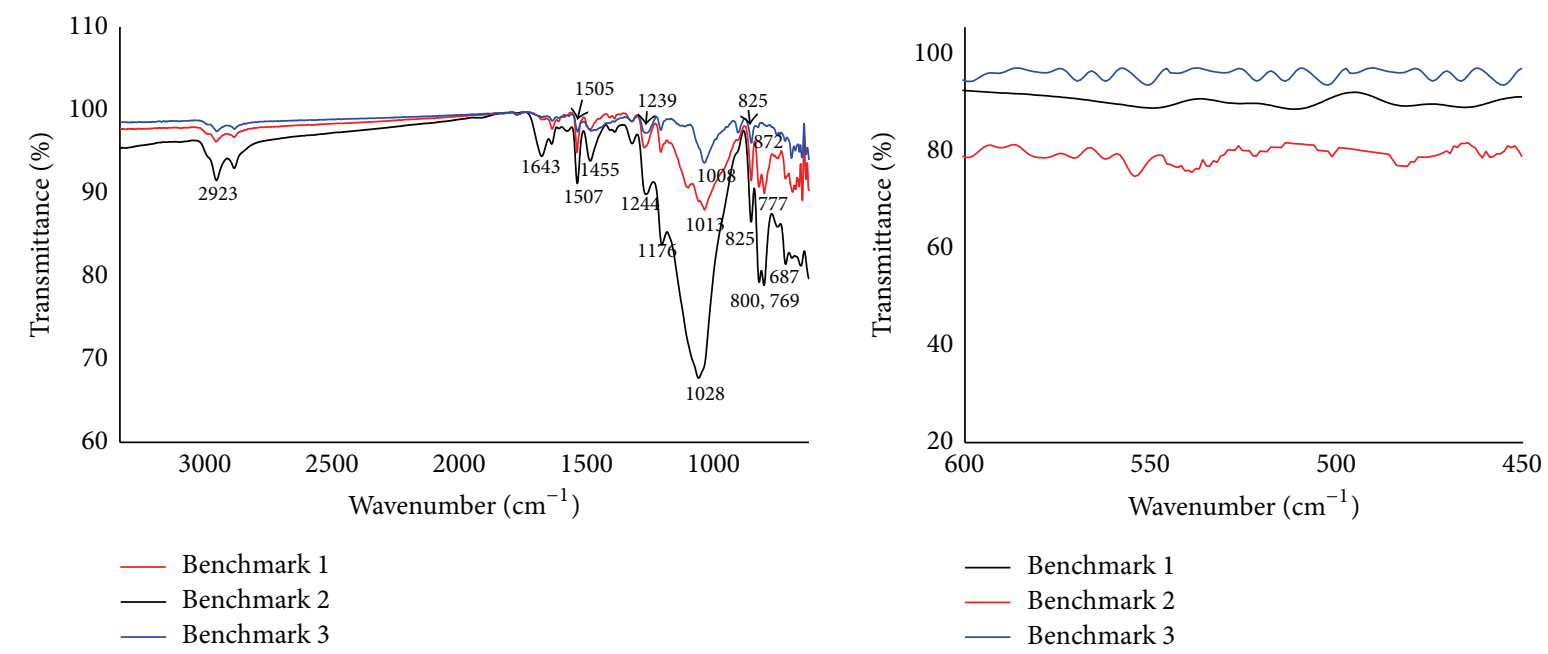

(b)

FIGURE 4: Comparative FTIR results of (a) STC1 with STC2 (b) benchmark products.

primer STC2 (Figure 5) show the homogenous dispersion of Zn particles; MIO flakes and other fillers indicate good compatibility between resin and filler particles, while in others, some agglomeration of silica particles occur which show the heterogenous dispersion indicating the weak compatibility between the resin and filler particles. This agglomeration of silica particles in benchmark coating generates internal stresses and cracks in coating so they do not provide sufficient corrosion protection of substrate. However, this uniform distribution of $\mathrm{Zn}$ and $\mathrm{MIO}$ particles reduces the internal 


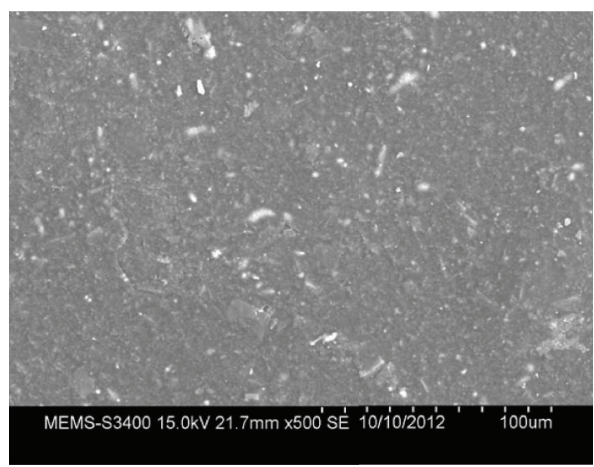

(a)

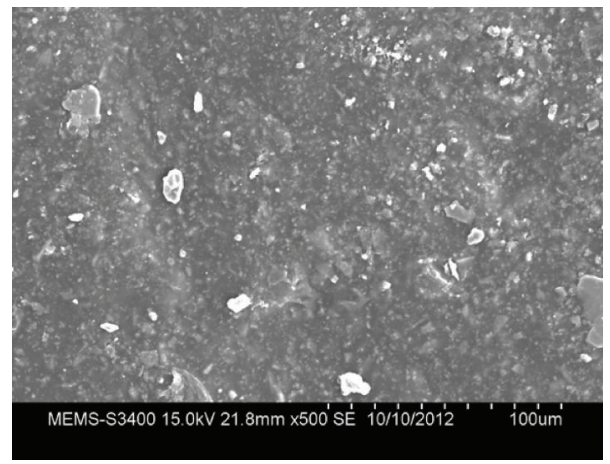

(c)

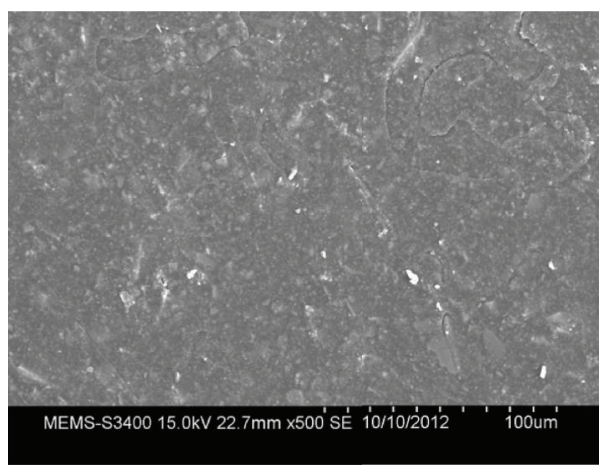

(b)

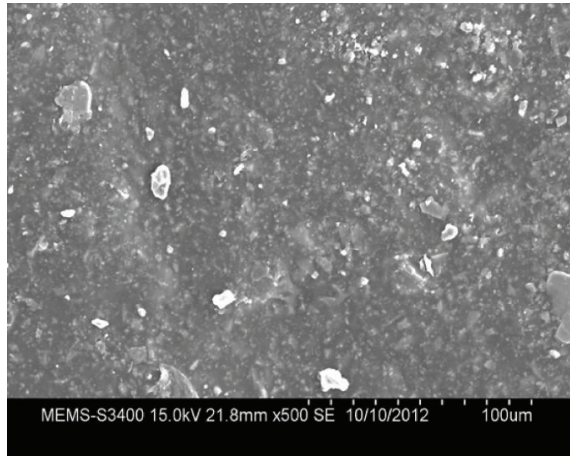

(d)

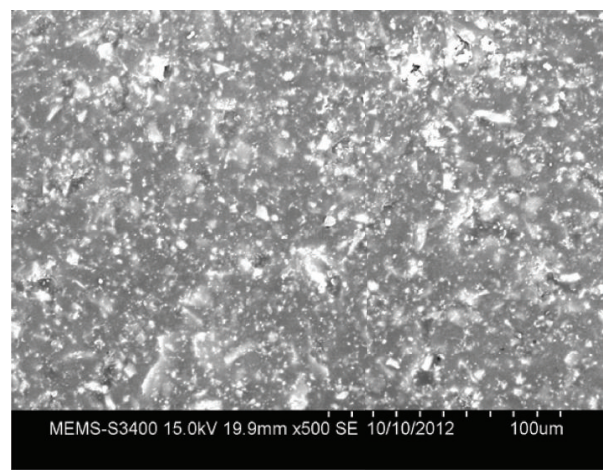

(e)

FIGURE 5: SEM micrographs of samples: (a) STC1, (b) STC2, (c) benchmark 1, (d) benchmark 2, and (e) benchmark 3.

stresses and cracking and also provides sufficient corrosion and barrier protection. EDAX images as shown in Figure 6 confirm the high percentage of zinc content (which is not available in benchmark coatings) in primer STC1 and presence of MIO in primer STC2, which are the main constituents providing cathodic and barrier protection, respectively.

3.3. Mechanical Testing. Taber abrasion test (ASTM D406010 ): in this test coated panels ( 4 in $\times 4$ in) were abraded with the help of abrasive wheels, wheel number CS-17 (Rubber + $\mathrm{Al}_{2} \mathrm{O}_{3}$ ); the wheel was $12.7 \mathrm{~mm}$ thick and had an external diameter of $51.9 \mathrm{~mm}$. A test of 1000 cycles was done to observe the weight loss in the coating. This test method has been useful in evaluating the abrasion resistance of attached coatings. Taber abrasion test showed the wear resistance of the coatings. As seen from Table 5, it is confirmed that both the STC1 and STC2 coatings behave as good wear resistance due to the presence of $\mathrm{Zn}$ and MIO flakes comparable to other products which indicate good crosslinking density of the primer.

Pull off adhesion test (ASTM D4541): this test determines either the greatest perpendicular force (in tension) that a surface area can bear before a plug of material is detached, or whether the surface remains intact at a prescribed force (pass/fail). Failure will occur along the weakest plane within the system comprised of the test fixture, adhesive, coating system, and substrate and will be exposed by the fracture surface. From Figure 7 and Table 5, it is observed that 


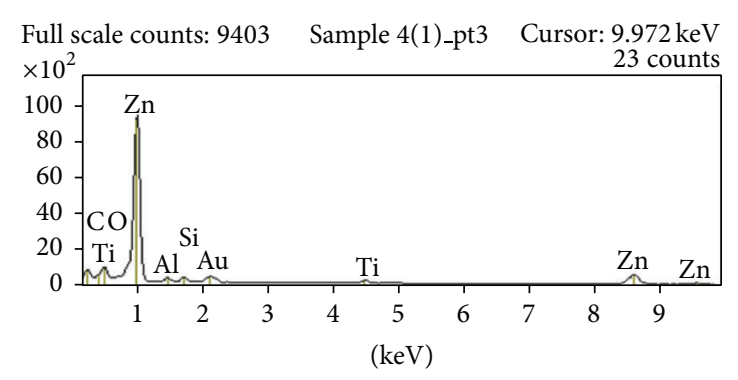

(a)

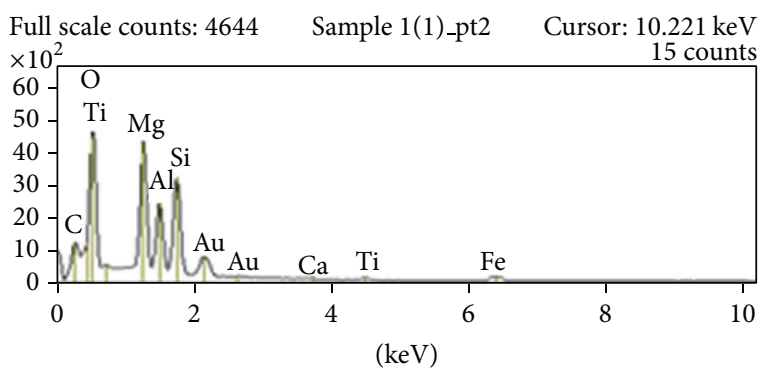

(c)

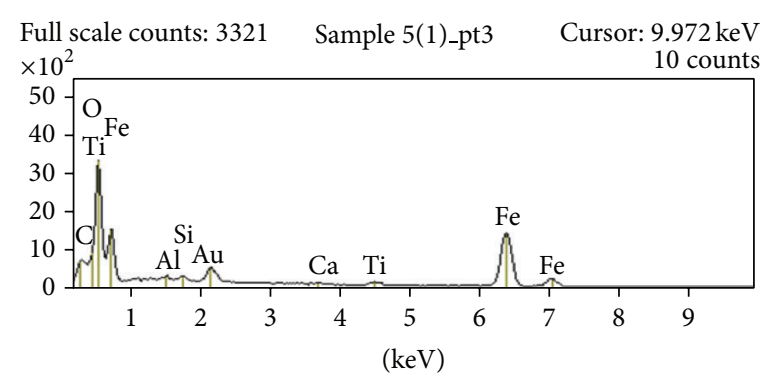

(b)

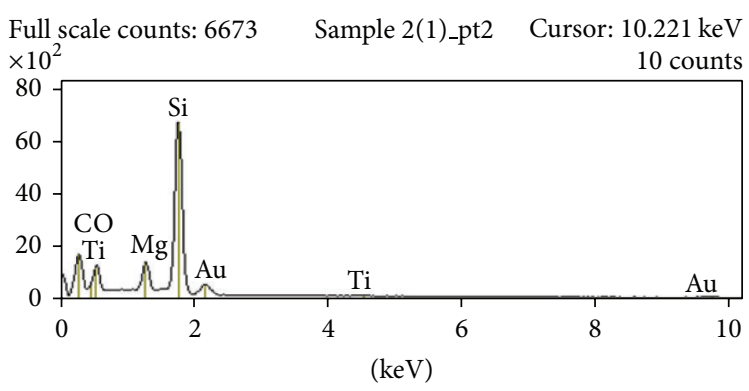

(d)

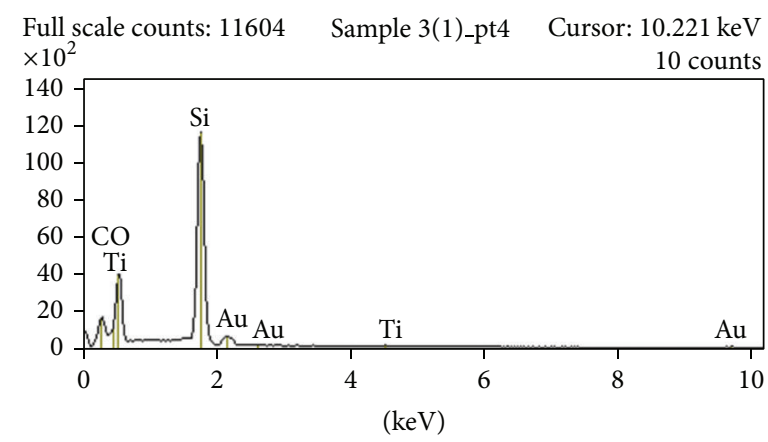

(e)

FIGURE 6: EDAX images of samples: (a) STC1, (b) STC2, (c) benchmark 1, (d) benchmark 2, and (e) benchmark 3.

the STC1 and STC2 underwent cohesive adhesion failure. This shows that the adhesion of the coatings was better than the other products, which experienced adhesion failures.

Results show that mechanical interlocking and chemical interactions throughout the interface are better in STCl and STC2 coatings as compared to other products in which adhesion strength decreased. The adhesion of STC2 is due to MIO flakes which is oriented parallel to the substrate and reacts well with resin which improves the chemical bonding between the MIO flakes and the resin. This gives improvement in interfacial strength.

Impact resistance test (ASTM D2247): this test method covers a procedure for rapidly deforming by impact a coating film and its substrate and for evaluating the effect of such deformation. It has been observed from Table 5 that the STC1 and STC2 systems surpassed the maximum height of impact and have maximum impact energy. Sine both systems (STC1 and STC2) were synthesized by using polyamidoamine hardener (polyamine with a long chain fatty acid) which is helpful in improving the coating flexibility, while in benchmark products, polyamine curatives have been added which is not sufficient to improving the flexibility of coating systems because of short chain length. In case of STC2, the MIO flakes in the coating induces stress relaxation, eliminate stress propagation, residual stresses, and reduce internal stresses. Figure 8 shows the panels of coating systems after impact test. The MIO flakes transform and absorb energy, which prevents crack propagation and growing up when the coating is subjected to an external stress and it will result in the improvement of the coating flexibility. The improvement of the coating flexibility will lead to improvement in the cohesion between the coating and substrate finally. In other products, there is no MIO flakes and zinc, which may be the result of their low impact strength in case of benchmarks 1 and 3.

Contact angle measurement (ASTM D7734): this measurement was done by goniometer. This test is useful for characterizing the wettability of surfaces. A low advancing contact angle value $\left(<45^{\circ}\right)$ is indicative of wetting and angles of 10 to $20^{\circ}$ are indicative of excellent wetting. Water can be used as a test liquid to establish whether a surface is hydrophilic (angle $<45^{\circ}$ ), hydrophobic (angle $>90^{\circ}$ ), or 


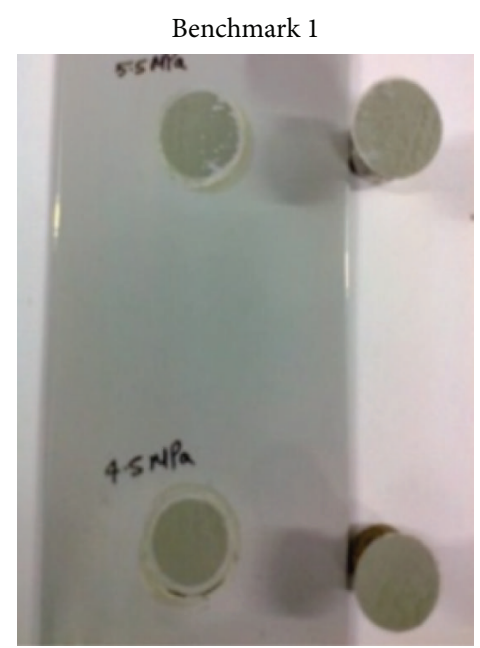

(a)

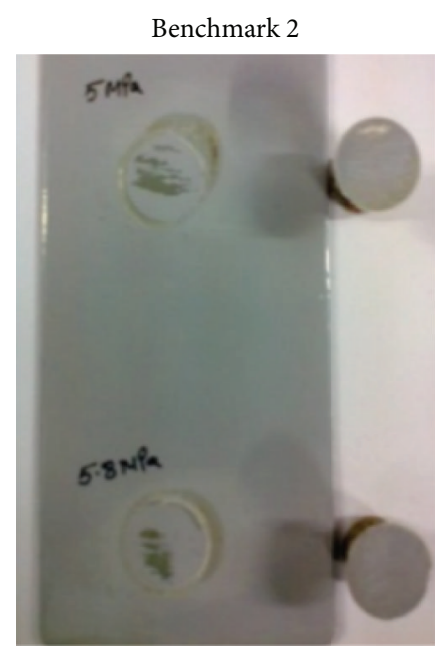

(b)

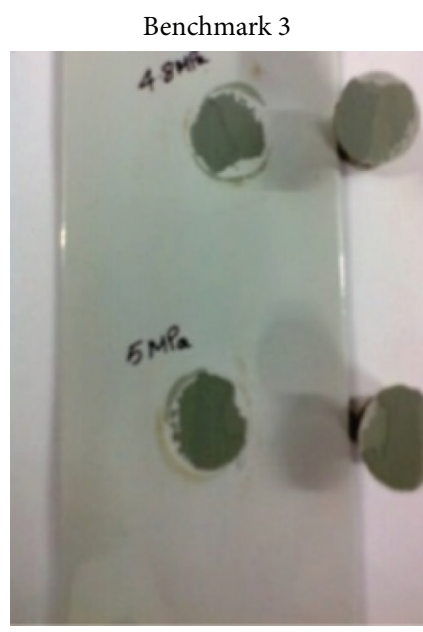

(c)

STC1

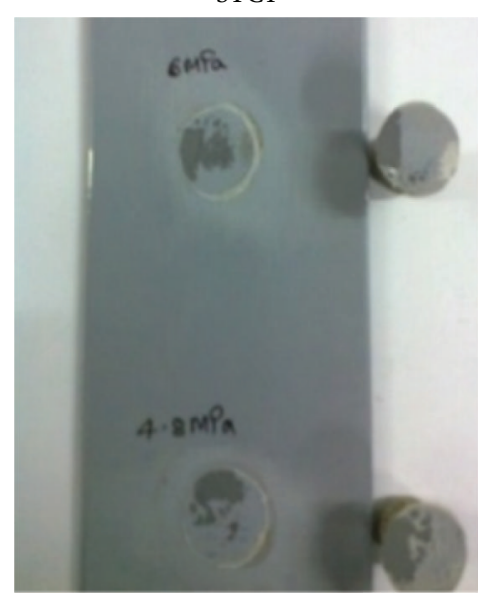

(d)

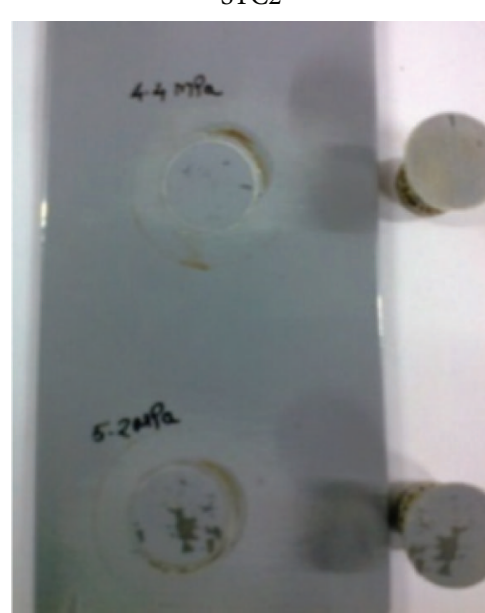

(e)

FIGURE 7: Pull off adhesion test images of samples: (a) benchmark 1, (b) benchmark 2, (c) benchmark 3, (d) STC1, and (e) STC2.

somewhere in between (angle of 45 to $90^{\circ}$ ). All coatings were hydrophilic in nature as their contact angle is less than $90^{\circ}$. For coating to be hydrophobic the contact angle must be equal to or greater than $90^{\circ}$ (Table 5 and Figure 9).

Tensile test (ASTM D638): this test method is designed to produce tensile property data for the control and specification of plastic materials by using ultimate tensile strength machine. From the tensile strength data shown in Table 5, it can be concluded that primer STC1 and primer STC2 show the tensile strength $10.37 \mathrm{MPa}$ and $10.58 \mathrm{MPa}$, which are higher as compared to other competitive products. This may be due to better bonding strength between epoxy matrix and the respective pigments ( $\mathrm{Zn}, \mathrm{MIO})$. When the coating under load, the stress is transferred from hard pigment to softer epoxy matrix. These pigments provide the good combination of strength and toughness to the coating, which results in good tensile strength.

Flexibility test (ASTM D522) and scratch resistance (ASTM D7027-13): flexibility test methods cover the determination of the resistance to cracking (flexibility) of attached organic coatings on substrates when elongated by using conical mandrel bend tester. The specimen is clamped against a conical mandrel and is bent around the mandrel by a roller mounted on a hand operated lever. The diameter of the mandrel at the point where the coating starts to crack can be determined from a scale marked on the specimen clamp. Scratch resistance test method is able to characterize the scratch resistance of polymers by measuring many significant material parameters. Table 5 shows that all the coating systems passed the maximum bending angle and scratch resistance test (Table 5).

\subsection{Corrosion Studies}

3.4.1. Salt Spray Test (ASTM B117). Samples were placed in corrosion-resistant self-supporting polyethylene casing. Salt spray test provides a controlled corrosive environment which has been utilized to produce relative corrosion resistance information for specimens of metals and coated metals exposed in a given test chamber. The coated panels were 


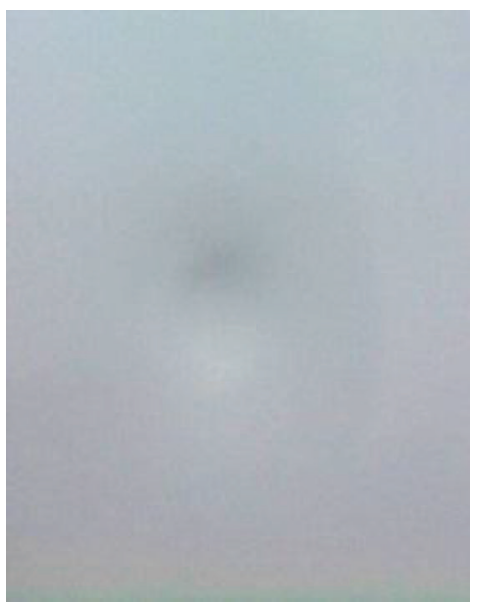

Benchmark 1

(a)

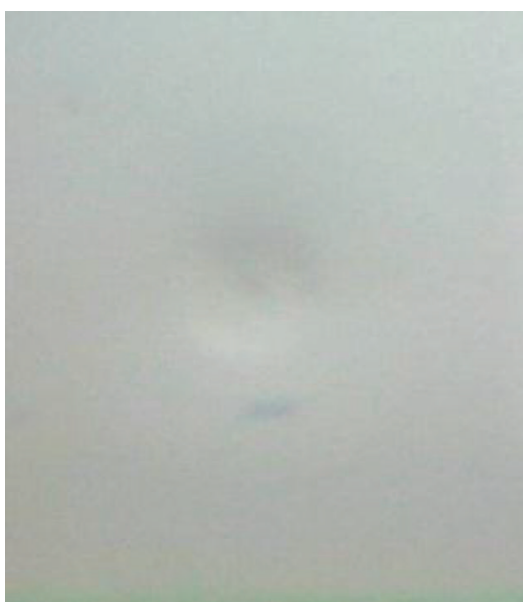

Benchmark 2

(b)

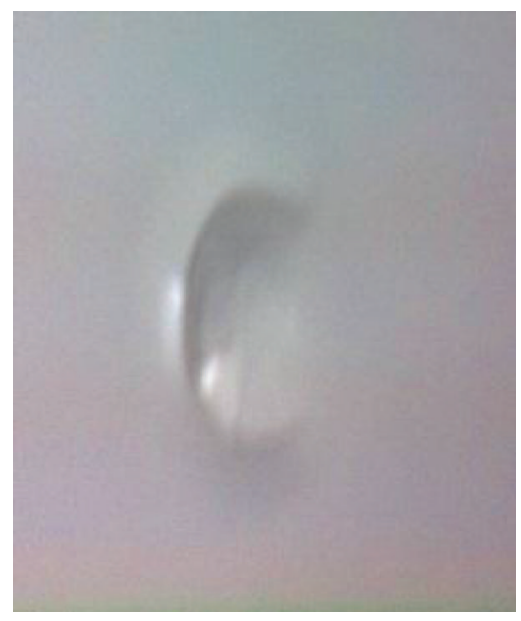

Benchmark 3

(c)

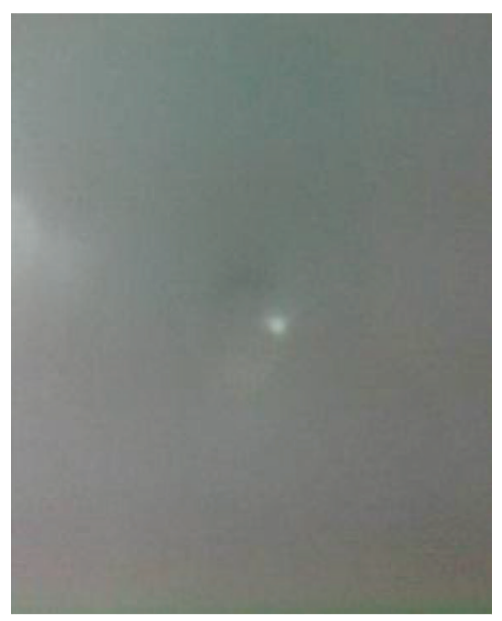

STC1

(d)

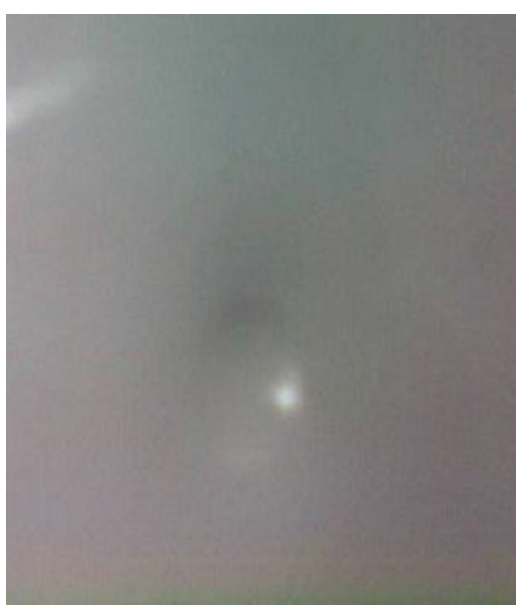

STC2

(e)

FIGURE 8: Impact resistance test of coated samples: (a) benchmark 1, (b) benchmark 2, (c) benchmark 3, (d) STC1, and (e) STC2.

exposed for 2000 hours in salt spray chamber. The salt spray chamber was maintained at $35^{\circ} \mathrm{C}$ containing $3.5 \% \mathrm{NaCl}$ solution. Figure 10 shows the coated panels at zero, 500, 1000, and 2000 hours. After 500 hours, initiation of blistering and delamination took place in benchmark coatings and number of blisters increased. Increased susceptibility of blistering and delamination may be due to the increased ionic permeability of the coating and the formation of amine carbamate (formed by absorbing carbon dioxide and moisture present in atmosphere by polyamine curative) over coating surface which is a clear indication of blushing. As a comparison to others, STC1 provided efficient protective function against delamination around scribed areas, ensured intense galvanic function of the primer. The other products show significant corrosion near the scribed areas, large blisters, and delamination. Table 6 summarizes the changes that took place in panels during salt spray exposure.

3.4.2. Electrochemical Test. Electrochemical tests were done by using an electrochemical analyzer $\mathrm{CH}$ 604C from $\mathrm{CH}$ instruments USA. A three-electrode glass cell equipped with a platinum counter electrode, an $\mathrm{Ag} / \mathrm{AgCl} / \mathrm{Cl}$ - reference electrode with uncoated and coated substrates was used for the electrochemical measurements. Electrochemical measurements were performed under extreme environmental conditions, consisting of an aqueous, air exposed sodium chloride $3.5 \% \mathrm{NaCl}$ solution at room temperature. Each sample masked by paraffin and only left $1.0 \mathrm{~cm}^{2}(1.0 * 1.0)$ area in the solution. The working electrode included an electrical connection wire, which was initially attaching the surface of sample with conducting glue. Samples were allowed to stabilize at their open circuit potential (OCP). The corrosion rate of coatings was measured by immersion studies conducted in $3.5 \mathrm{wt} . \% \mathrm{NaCl}$ solution at room temperature after $2000 \mathrm{hrs}$ of salt spray exposure.

3.4.3. Electrochemical Polarization Test. Potentiodynamic polarization was performed at $0.01 \mathrm{~V} / \mathrm{sec}$ scan rate. From the polarization curves (Figure 11) and the data from Table 6, it is 


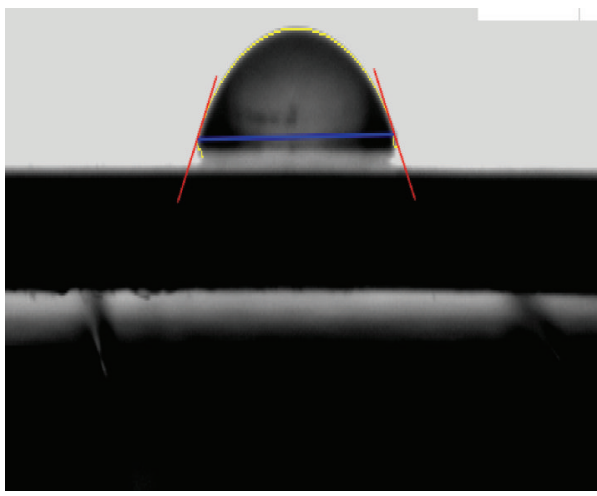

(a)

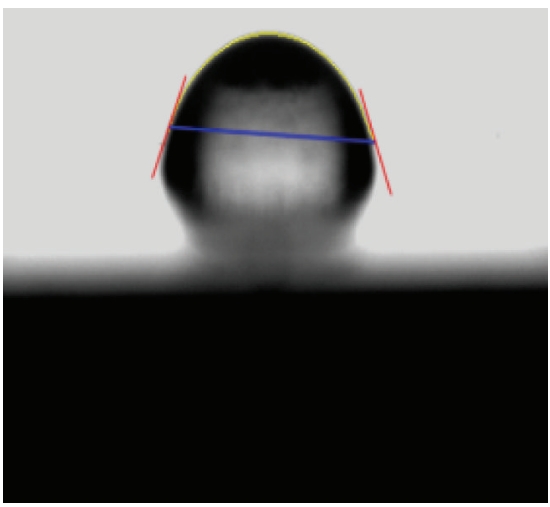

(c)

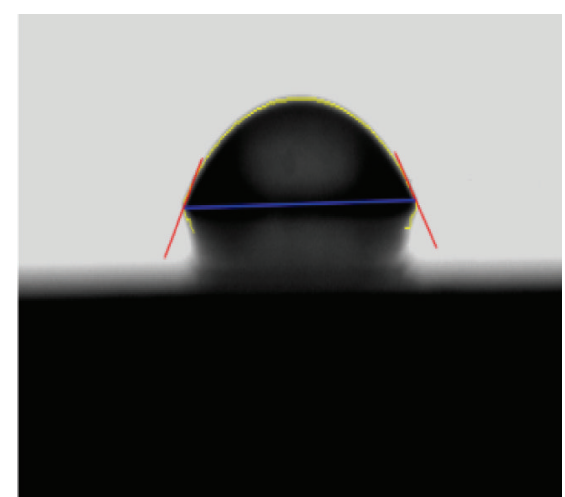

(b)

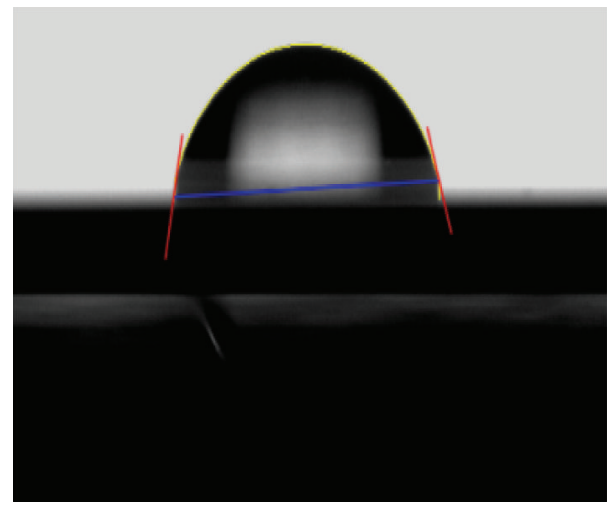

(d)

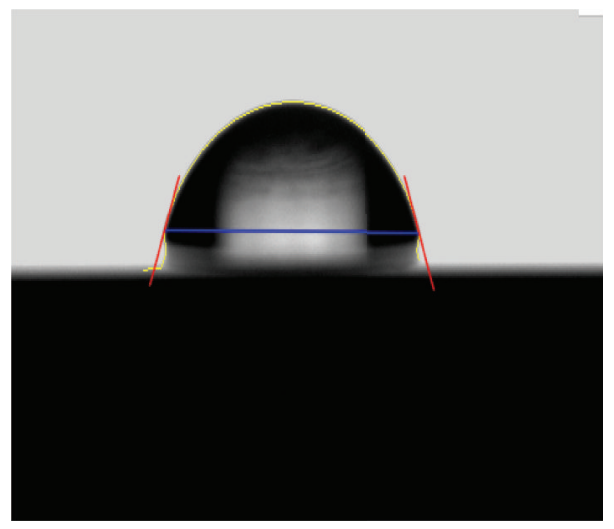

(e)

FIGURE 9: Contact angle test of coated samples: (a) benchmark 1, (b) benchmark 2, (c) benchmark 3, (d) STC1, and (e) STC2.

clear that the STC1 has higher OCP and lower current density $\left(2.9 \times 10^{-7} \mathrm{~A} \mathrm{~cm}^{-2}\right)$ and corrosion rate as compared to MIO based STC2 and other benchmark coatings. This is due to the presence of zinc oxide, which provides cathodic protection to the substrate initially.

Later due to formation of the corrosion product, that is, $\mathrm{ZnO}$, the zinc in the system gets consumed and the formed product which provides barrier protection to the substrate. In the case of STC2, the MIO flakes are responsible for providing barrier protection, but since there is no zinc, its corrosion rate is higher than STC1. So it is confirmed that the other products have higher current densities and corrosion rate than the STC1 and STC2 due to their lack of cathodic protection as well as less barrier protection because of the absence of zinc and MIO flakes in coating material.

3.4.4. Durability Test. All electrochemical impedance spectroscopy (EIS) spectra were acquired at the open circuit potential in a frequency range from $10 \mathrm{~Hz}$ to $1000 \mathrm{~Hz}$ with ac excitation amplitude of $5 \mathrm{mV} / \mathrm{s}$ in a $3.5 \% \mathrm{NaCl}$ solution at room temperature. The durability of the coating systems was estimated by exposing the samples at zero, 500, 1000, and 2000 hours. The pore resistance of the coatings is calculated by plotting bode plots at respective hours.

Initially the STC1 shows excellent barrier protection owing to the homogenous distribution of zinc particles. It has 


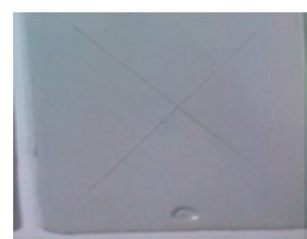

At 0 hour

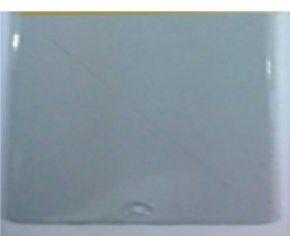

At 0 hour

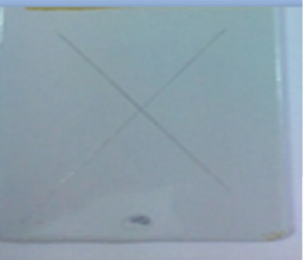

At 0 hour

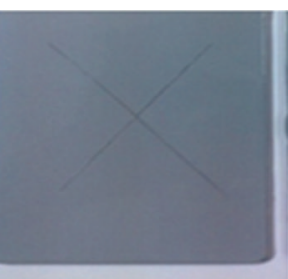

At 0 hour

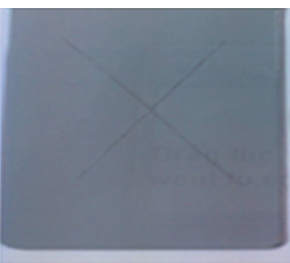

At 0 hour

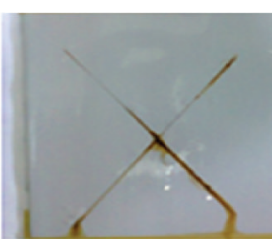

At 500 hours

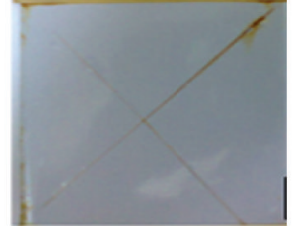

At 500 hours

(b)

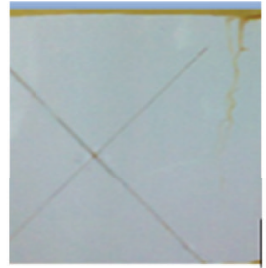

At 500 hours

(c)

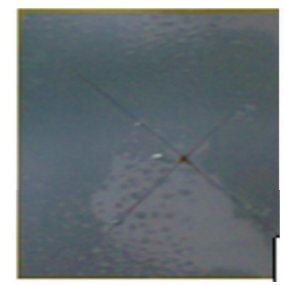

At 500 hours

(d)

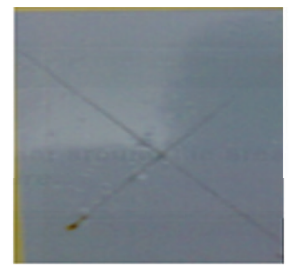

At 500 hours

(a)

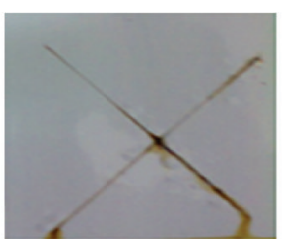

At 1000 hours

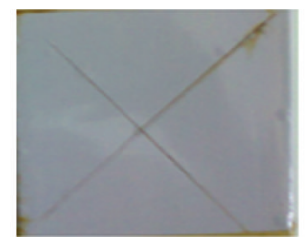

At 1000 hours

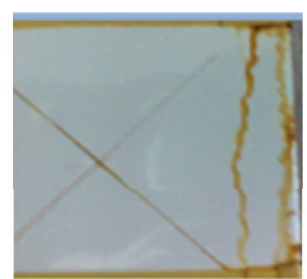

At 1000 hours

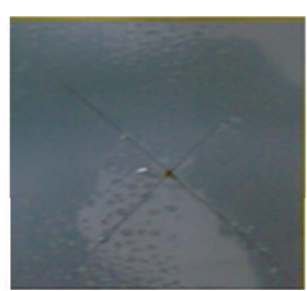

At 1000 hours

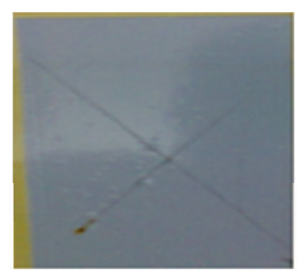

At 1000 hours

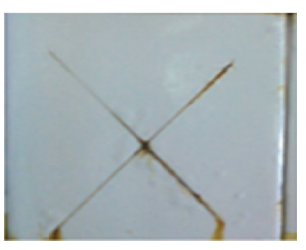

At 2000 hours

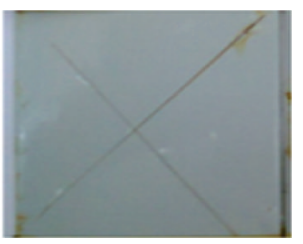

At 2000 hours

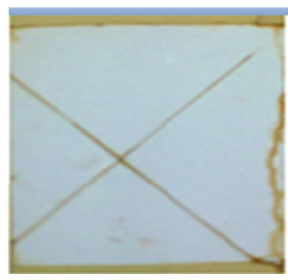

At 2000 hours

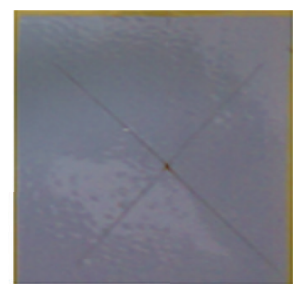

At 2000 hours

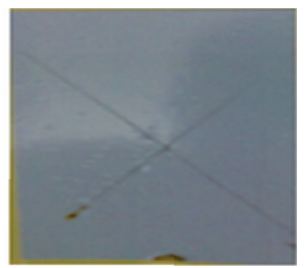

At 2000 hours

(e)

FIGURE 10: Salt spray images of coated panels at 0, 500, 1000, and 2000 hours; (a) benchmark 1, (b) benchmark 2, (c) benchmark 3, (d) STC1, and (e) STC2.

been observed that from zero to 500 hours, there is decrease in pore resistance from $\log (\mathrm{Z} / \mathrm{ohm}) 6.5$ to 4.8 ; this may be due to initiation of corrosion process due to percolation of the electrolyte solution. After that from 500 to $2000 \mathrm{hrs}$, there is not much change in pore resistance due to the consumed zinc that formed the corrosion product as $\mathrm{ZnO}$ as shown in bode plots (Figure 12). This is attributed to filling up of void spaces of the coatings by corrosion products of $\mathrm{Zn}$, which provide additional barrier protection. In STC2, the MIO plays a key role for providing barrier protection to the substrate. It provides the permeability, allowing the transport of water vapor into and out of the film which is helpful in preventing 
TABLE 5: Comparative mechanical test results of different kinds of surface tolerant coatings.

\begin{tabular}{|c|c|c|c|c|c|}
\hline & Benchmark 1 & Benchmark 2 & Benchmark 3 & STC1 & STC2 \\
\hline \multirow{2}{*}{ Pull off adhesion (Mpa) } & $5 \mathrm{Mpa}$ & $5.4 \mathrm{Mpa}$ & 4.9 Mpa & $5.4 \mathrm{Mpa}$ & $5.2 \mathrm{Mpa}$ \\
\hline & Adhesion failure & Cohesive failure & Adhesion failure & Cohesive failure & Cohesive failure \\
\hline $\begin{array}{l}\text { Impact energy, load: } \\
4.730 \mathrm{~kg} \text {, } \\
\text { max height: } 23^{\prime \prime}\end{array}$ & $23.18 \mathrm{~J}$ & $26.88 \mathrm{~J}$ & $18.54 \mathrm{~J}$ & $26.88 \mathrm{~J}$ & $26.88 \mathrm{~J}$ \\
\hline Scratch resistance & $10 \mathrm{Kg}$ : passed & $10 \mathrm{Kg}$ : passed & $10 \mathrm{Kg}$ : passed & $10 \mathrm{Kg}$ : passed & $10 \mathrm{Kg}$ : passed \\
\hline Flexibility & $140^{\circ}$ : passed & $140^{\circ}:$ passed & $140^{\circ}$ : passed & $140^{\circ}:$ passed & $140^{\circ}:$ passed \\
\hline Tensile strength & $8.46 \mathrm{Mpa}$ & $5.76 \mathrm{MPA}$ & $5.07 \mathrm{MPa}$ & 10.37 MPa & $10.58 \mathrm{MPa}$ \\
\hline $\begin{array}{l}\text { Taber abrasion results by } \\
\text { weight loss (gm) }\end{array}$ & 0.1277 & 0.0945 & 0.2080 & 0.0981 & 0.1073 \\
\hline Contact angle & 55.34 & 52.34 & 62.24 & 74.74 & 67.20 \\
\hline
\end{tabular}

TABLE 6: Comparative corrosion test results of different kinds of surface tolerant coatings.

\begin{tabular}{|c|c|c|c|c|c|c|c|c|}
\hline \multirow{2}{*}{ Systems } & \multicolumn{3}{|c|}{ Salt spray test (SST) } & \multicolumn{4}{|c|}{$\log (Z / O h m)$} & \multirow{2}{*}{$\begin{array}{l}\text { Corrosion rate } \\
\text { (mpy-miles per } \\
\text { year) }\end{array}$} \\
\hline & $0-500$ hours & 500-1000 hours & 1000-2000 hours & 0 hour & 500 hours & 1000 hours & $\begin{array}{c}2000 \\
\text { hours }\end{array}$ & \\
\hline Benchmark 1 & $\begin{array}{c}\text { Initiation of } \\
\text { blistering at } 300 \\
\text { hours }\end{array}$ & $\begin{array}{c}\text { Number of } \\
\text { blisters incresed }\end{array}$ & $\begin{array}{c}\text { Large blisters at } \\
\text { the centre and } \\
\text { edges. }\end{array}$ & 6.5 & 4.8 & 3.8 & 2 & $3.036 \mathrm{mpy}$ \\
\hline Benchmark 2 & $\begin{array}{c}\text { Initiation of } \\
\text { blistering at } 350 \\
\text { hours } \\
\end{array}$ & $\begin{array}{c}\text { Number of } \\
\text { blisters incresed }\end{array}$ & $\begin{array}{c}\text { Number of } \\
\text { blisters increased }\end{array}$ & 5.5 & 4.2 & 3.3 & 2.9 & $0.795 \mathrm{mpy}$ \\
\hline Benchmark 3 & No blistering & $\begin{array}{l}\text { Large blisters at } \\
\text { the centre and } \\
\text { edges }\end{array}$ & $\begin{array}{l}\text { Large number of } \\
\text { small edges }\end{array}$ & 3.8 & 3.2 & 3 & 2.9 & $0.420 \mathrm{mpy}$ \\
\hline STC1 & No blistering & No blistering & $\begin{array}{c}\text { Initiation of } \\
\text { blistering at } 1600 \\
\text { hours }\end{array}$ & 7.5 & 4.8 & 4.2 & 4.1 & $0.133 \mathrm{mpy}$ \\
\hline STC2 & No blistering & No blistering & $\begin{array}{c}\text { Initiation of } \\
\text { blistering at } 1500 \\
\text { hours }\end{array}$ & 6.5 & 5.5 & 4.8 & 4.1 & $0.311 \mathrm{mpy}$ \\
\hline
\end{tabular}

blistering and delamination, even under severe temperature gradients. From Figure 13, it can be seen that initially the STC1 shows higher value of coating resistance and the slope is less steep than the STC2. The results show that the coatings at this time were good shielding layers with large impedances and the matrix was protected well. After $500 \mathrm{hrs}$ the pore resistance started decreasing, assuming that the electrolyte solution was penetrating through the pores of the coatings (Figure 13 and Table 6). This could be because there was no path in the coatings that allowed the electrolyte to reach the substrate with increasing exposure time. The coating layer was gradually attacked and thinned down by the electrolyte, which led to a decrease in the coating resistance $\left(R_{p}\right)$ because electrolyte was transported to the metal substrate through ionic conducting paths in the coating. The other benchmark products show relatively less coating resistance.

\section{Conclusions}

(1) Zinc dust pigmented surface tolerant coating (STC1) and micaceous iron oxide pigmented surface tolerant

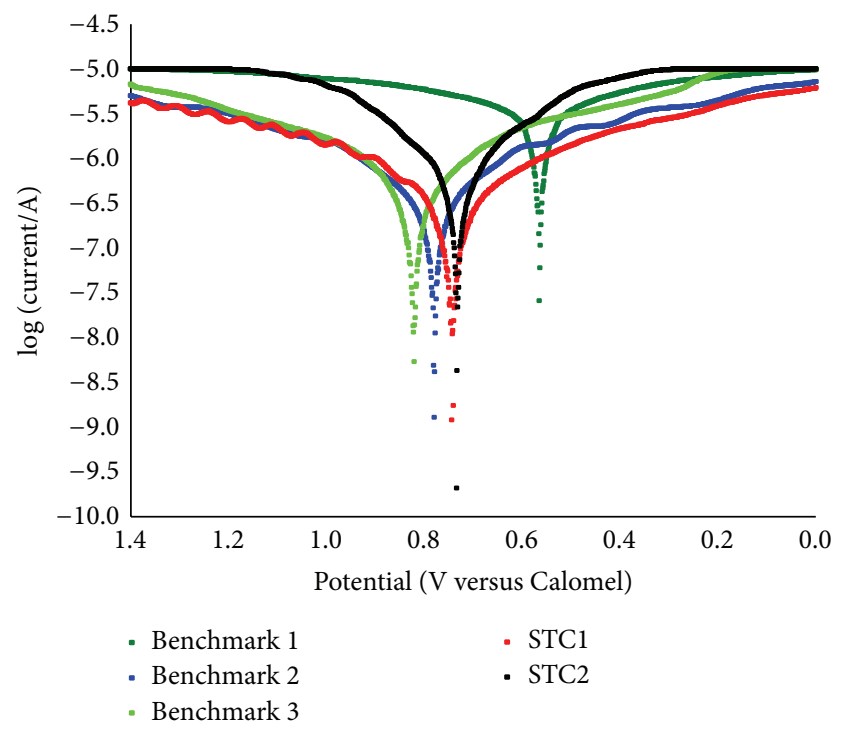

FIgURE 11: Comparative Tafel plots of STC1 and 2 and benchmarks 1,2 , and 3 . 

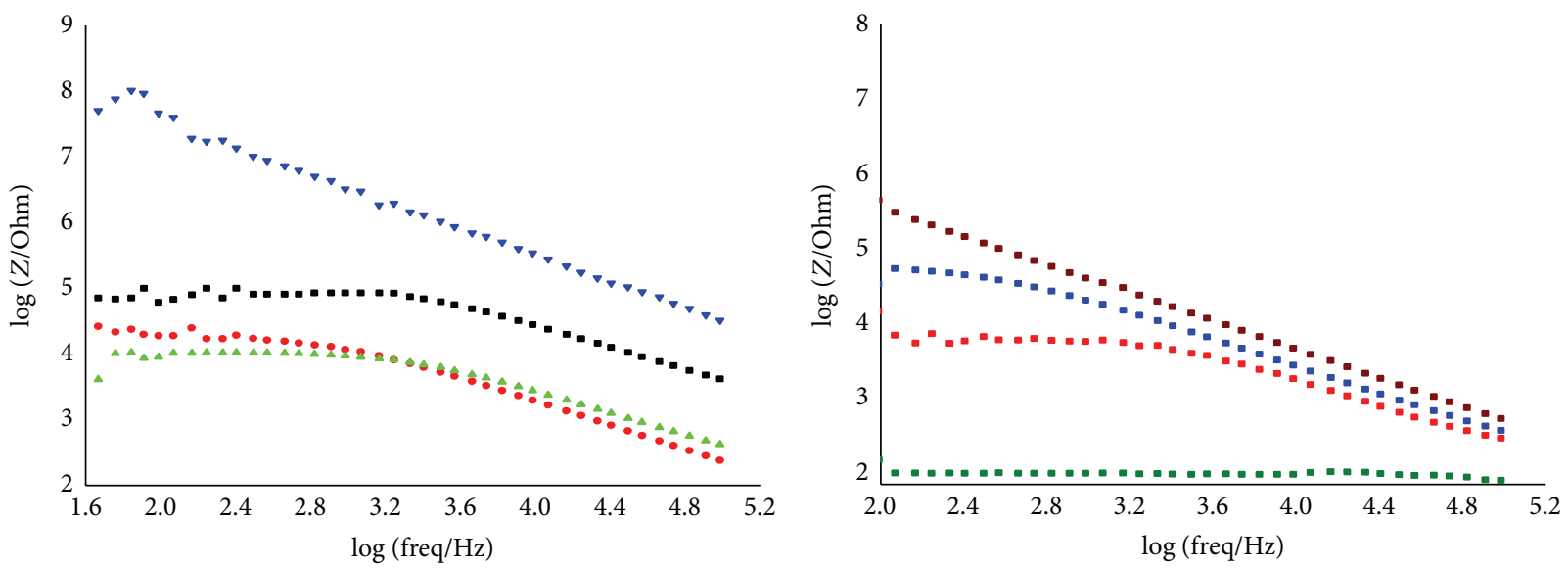

- 500 hours

\& 2000 hours

- 500 hours

- 1000 hours

0 hour

- 1000 hours

- 0 hour

- 2000 hours

(a)

(b)
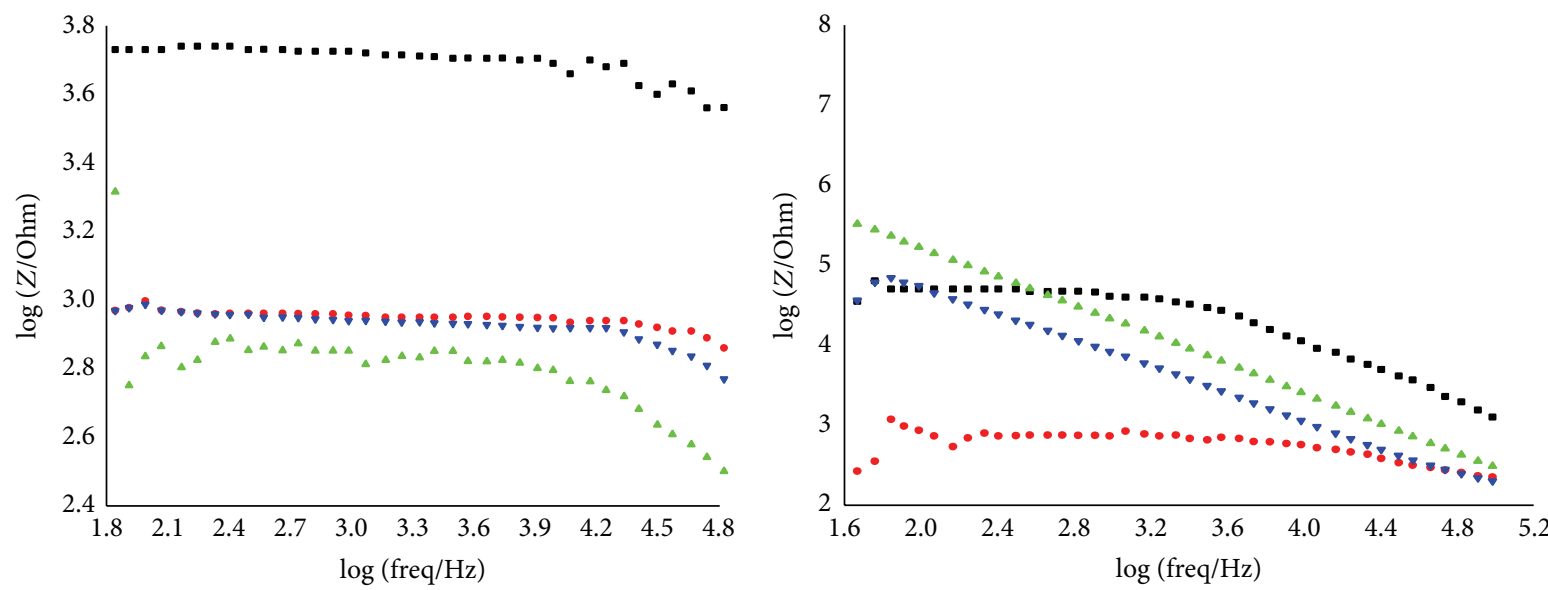

- 0 hours

- 500 hours

- 2000 hours

500 hours

- 2000 hours

- 0 hour

- 1000 hours

(c)

(d)

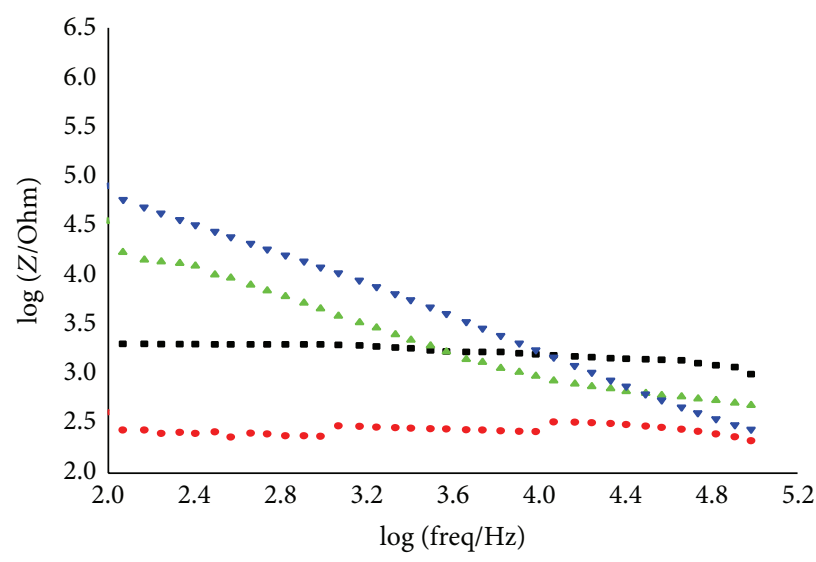

- 1000 hours

- 500 hours

- 2000 hours

- 0 hour

(e)

FIGURE 12: Bode plots of various coating systems: (a) benchmark 1, (b) benchmark 2, (c) benchmark 3, (d) STC1, and (e) STC2. 


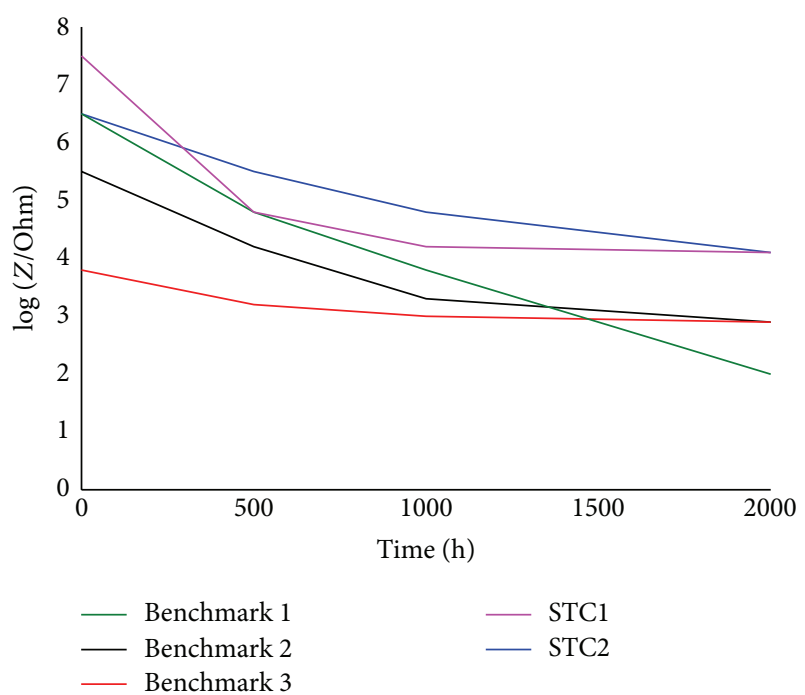

FIGURE 13: Pore resistance with time for various coating systems.

coating (STC2) were found to form a uniform coating film over moist, oil contaminated, and surface prepared hot rolled sheets. Excellent surface compatibility to wet surface and good interfacial adhesion may be due to low surface tension $(28 \mathrm{~N} / \mathrm{m})$ of the coatings compared to competitive coatings $(>30 \mathrm{~N} / \mathrm{m})$.

(2) The results of impact resistance, tensile strength, abrasion resistance, scratch resistance, flexibility, and pull off adhesion were found superior than other available products.

(3) Anticorrosive pigments such as zinc dust (responsible for superior cathodic protection because of its lower reduction potential than iron) and MIO (flaky shape which provide torturous path to the penetration of corrosive electrolytes) in the system have shown significant resistance against migration of chloride ions and water and the free space between the particle and the resin was less and thus restricted the penetration of electrolyte through the pores in the coating film. This is evident for high pore resistance over time in $3.5 \mathrm{wt} . \% \mathrm{NaCl}$ solution. The rate of corrosion is also found $2 / 3$ times less in $3.5 \mathrm{wt} . \% \mathrm{NaCl}$ as compared to competitive products.

(4) Marine simulation corrosion test as per ASTM B 117 has shown significant delay in blister formation. This is due to presence of anticorrosive pigments.

\section{Conflict of Interests}

The authors declare that there is no conflict of interests regarding the publication of this paper.

\section{Acknowledgments}

The authors would like to thank Stanvac-Superon group for providing funding and IIT Bombay and Tata Steel Industry for providing research facilities for this work. The authors would like to thank all the Research Associate team also.

\section{References}

[1] G. C. Soltz, "The effects of substrate contaminates on the life of epoxy coatings in sea water," NSRP Report 0329, National Shipbuilding Research Program, 1991.

[2] S. B. R. Appleman, S. Boocock, R. E. F. Weaver, and G. C. Soltz, "Effect of surface contaminates on coating life," U.S. Department of Transportation Federal Highway Administration Publication FHWA-RD-91-011, 1991.

[3] National Steel and Shipbuilding NSRP Report, "Power Tool Cleaning an alternate for abrasive blasting," 1993.

[4] J. W. Peart, Evaluation of Coatings Applied on Less than Ideal Surfaces, withPeterson builders, inc, sturgeon bay, Wis, USA, 1995.

[5] "Curing Agent for Epoxy Resins," Three Bond Technical News, 1990.

[6] N. Rajgopalan and A. S. Khanna, "Effect of nano-ZnO in lowering yellowing of aliphatic amine cured DGEBA-based epoxy coatings on UV exposure," International Journal of Scientific and Research, vol. 3, no. 4, 2013.

[7] H. Lee and K. Neville, Epoxy Resins Their Synthesis and Characterization and Curing of Epoxy Resins, Their Applications and Technology, McGraw Hill.

[8] Z. W. Wicks, F. N. Jones, and S. P. Pappas, "Organic coatings: science and technology," Dyes and Pigments, vol. 45, pp. 85-86, 2000.

[9] L. S. Salem, “Epoxies for steel," Journal of Protective Coatings and Linings, vol. 13, pp. 77-98, 1996.

[10] M. Ebert et al., Polymer, vol. 32, no. 3, p. 139, 1991.

[11] S. Swier, G. van Assche, W. Vuchelen, and B. Van Mele, "Role of complex formation in the polymerization kinetics of modified epoxy-amine systems," Macromolecules, vol. 38, no. 6, pp. 2281$2288,2005$.

[12] S. Shreepathi, P. Bajaj, and B. P. Mallik, "Electrochemical impedance spectroscopy investigations of epoxy zinc rich coatings: role of $\mathrm{Zn}$ content on corrosion protection mechanism," Electrochimica Acta, vol. 55, no. 18, pp. 5129-5134, 2010.

[13] P. A. Sørensen, S. Kiil, K. Dam-Johansen, and C. E. Weinell, "Anticorrosive coatings: a review," Journal of Coatings Technology Research, vol. 6, no. 2, pp. 135-176, 2009.

[14] A. Ruvolo-Filho and M. Magaton, "Evaluating barrier properties of acrylic polyurethane and aliphatic polyurethane coatings loaded with micaceous iron oxide or red iron oxide," Polymer. Plastics Technology and Engineering, vol. 48, no. 7, pp. 682-695, 2009.

[15] C. Giúdice, J. C. Benftez, and M. M. Linares, "Zinc-rich epoxy primers based on lamellar zinc dust," Surface Coatings International, vol. 80, no. 6, pp. 279-284, 1997. 

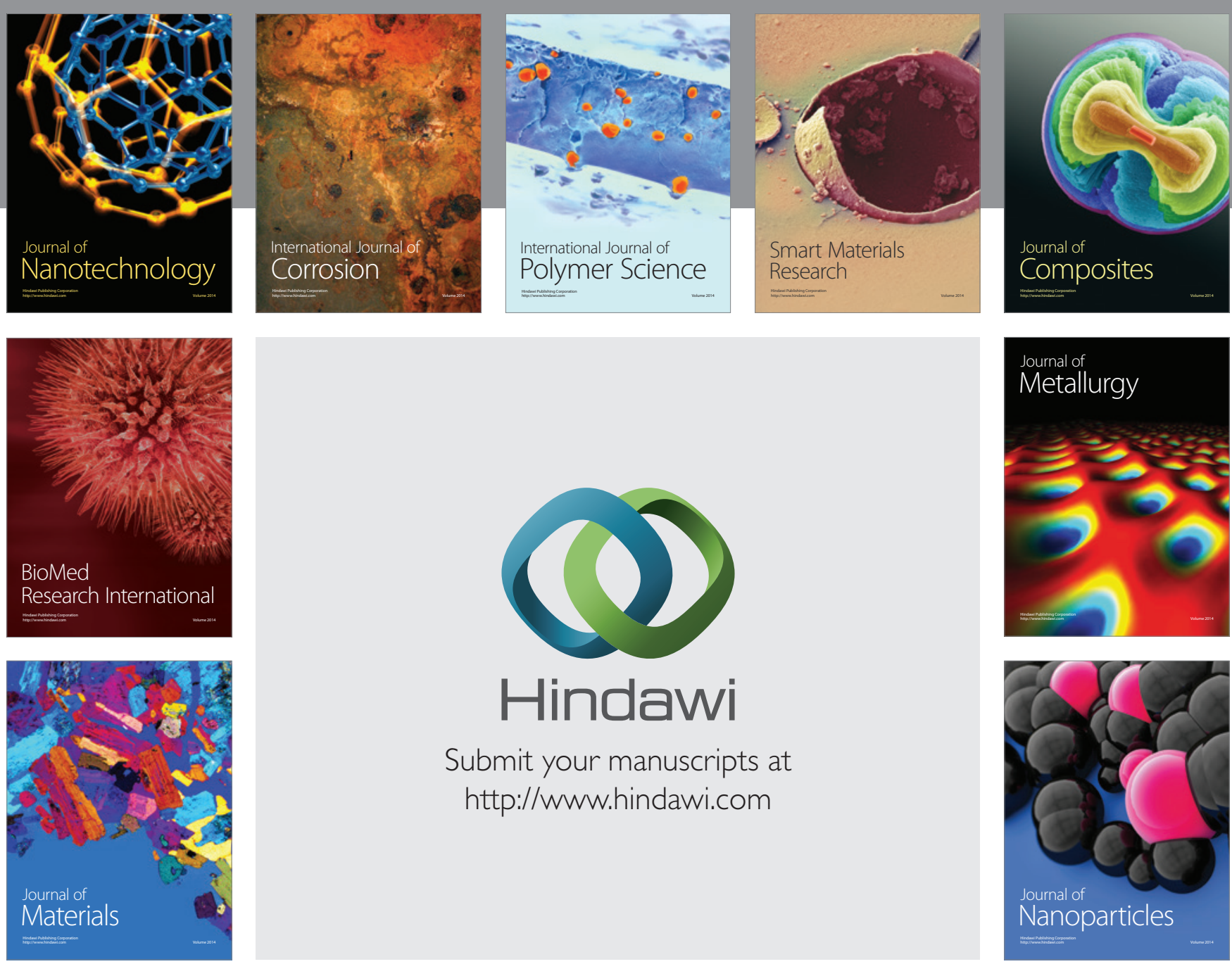

Submit your manuscripts at http://www.hindawi.com
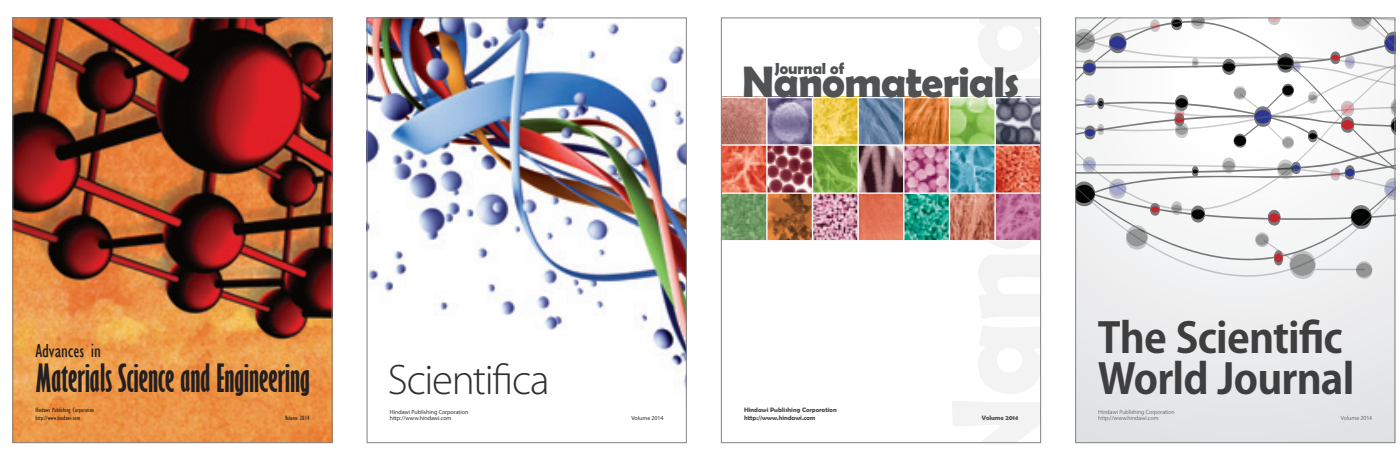

\section{The Scientific World Journal}
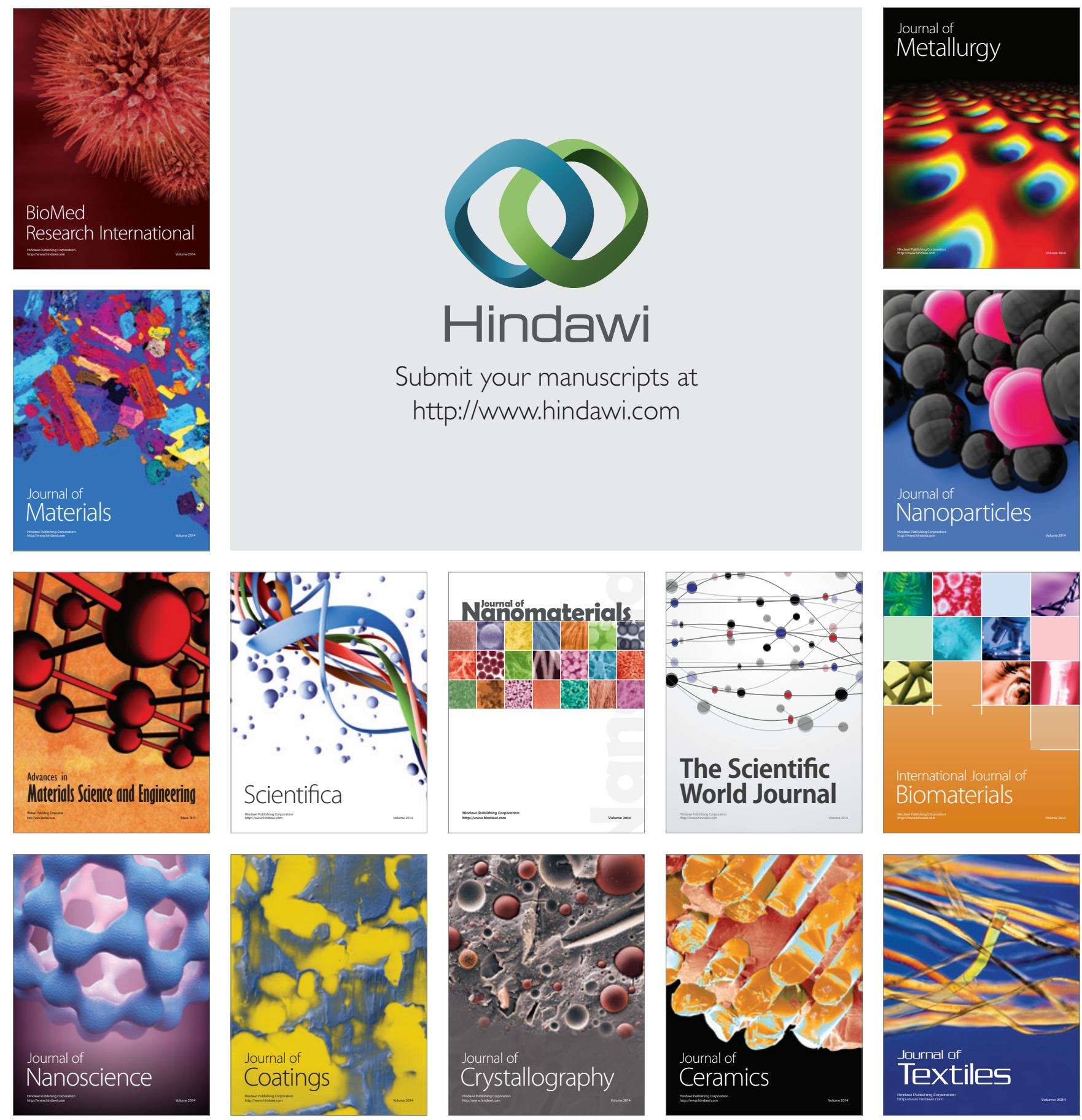